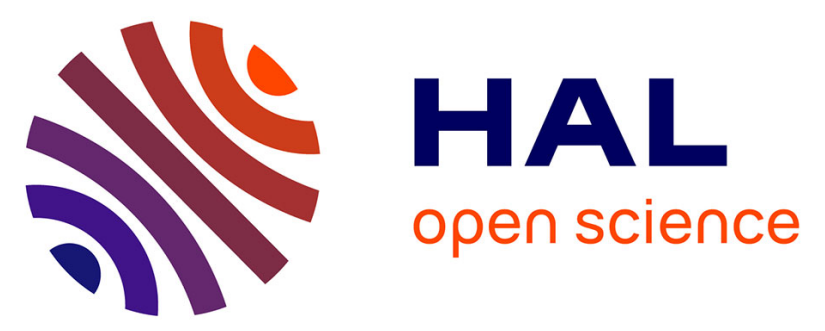

\title{
Earthquake synchrony and clustering on Fucino faults (Central Italy) as revealed from in situ Cl-36 exposure dating
}

\author{
Lucilla Benedetti, Isabelle Manighetti, Yves Gaudemer, Robert Finkel, \\ Jacques Malavieille, Khemrak Pou, Maurice Arnold, Georges Aumaitre, Didier \\ Bourles, Karim Keddadouche
}

\section{To cite this version:}

Lucilla Benedetti, Isabelle Manighetti, Yves Gaudemer, Robert Finkel, Jacques Malavieille, et al.. Earthquake synchrony and clustering on Fucino faults (Central Italy) as revealed from in situ Cl36 exposure dating. Journal of Geophysical Research: Solid Earth, 2013, 118 (9), pp.4948-4974. 10.1002/jgrb.50299 . hal-00903460

\section{HAL Id: hal-00903460 https://hal.science/hal-00903460}

Submitted on 21 Aug 2020

HAL is a multi-disciplinary open access archive for the deposit and dissemination of scientific research documents, whether they are published or not. The documents may come from teaching and research institutions in France or abroad, or from public or private research centers.
L'archive ouverte pluridisciplinaire HAL, est destinée au dépôt et à la diffusion de documents scientifiques de niveau recherche, publiés ou non, émanant des établissements d'enseignement et de recherche français ou étrangers, des laboratoires publics ou privés. 


\title{
Earthquake synchrony and clustering on Fucino faults (Central Italy) as revealed from in situ ${ }^{36} \mathrm{Cl}$ exposure dating
}

\author{
Lucilla Benedetti, ${ }^{1}$ Isabelle Manighetti, ${ }^{2}$ Yves Gaudemer, ${ }^{3}$ Robert Finkel, ${ }^{1,4}$ \\ Jacques Malavieille, ${ }^{5}$ Khemrak Pou, ${ }^{1}$ Maurice Arnold, ${ }^{1}$ Georges Aumaître, ${ }^{1}$ \\ Didier Bourlès, ${ }^{1}$ and Karim Keddadouche ${ }^{1}$ \\ Received 27 December 2012; revised 15 July 2013; accepted 16 July 2013; published 6 September 2013.
}

[1] We recover the Holocene earthquake history of seven seismogenic normal faults in the Fucino system, central Italy. We collected 800 samples from the well-preserved limestone scarps of the faults and modeled their ${ }^{36} \mathrm{Cl}$ concentrations to derive their seismic exhumation history. We found that $>30$ large earthquakes broke the faults in synchrony over the last $12 \mathrm{ka}$. The seven faults released strain at the same periods of time, 12-9 ka, 5-3 ka, and 1.5-1 ka. On all faults, the strain accumulation and release occurred in 3-6 ka supercycles, each included a $3-5 \mathrm{ka}$ phase of slow $(\leq 0.5-2 \mathrm{~mm} / \mathrm{yr})$ strain accumulation in relative quiescence, followed by a cluster of three to four large earthquakes or earthquake sequences that released most of the strain in $<1-2 \mathrm{ka}$. The large earthquakes repeated every $0.5 \pm 0.3 \mathrm{ka}$ during the paroxysmal phases and every $4.3 \pm 0.9 \mathrm{ka}$ between those phases. Earthquakes on the northern faults produced twice larger surface slips $(\sim 2 \mathrm{~m})$ and had larger magnitudes (Mw 6.2-6.7) than those on the southern faults. On most faults, the relative strain level was found to control the amount of slip and the time of occurrence of the next large earthquake. Faults entered a phase of clustered activity once they had reached a specific relative strain threshold. The Tre Monti fault is identified as the most prone to break over the next century. Our data document earthquake synchrony and clustering at a broader space and time scale than has been reported to date.

Citation: Benedetti, L., I. Manighetti, Y. Gaudemer, R. Finkel, J. Malavieille, K. Pou, M. Arnold, G. Aumaître, D. Bourlès, and K. Keddadouche (2013), Earthquake synchrony and clustering on Fucino faults (Central Italy) as revealed from in situ 36Cl exposure dating, J. Geophys. Res. Solid Earth, 118, 4948-4974, doi:10.1002/jgrb.50299.

\section{Introduction}

[2] On any active fault, earthquake geology seeks to know: When is the next large ( $M w \geq 6-7$ depending on the region) earthquake due, where will it occur, and what will be its size? Answering these questions is necessary to assess seismic hazard, as to understand the physics of faults and earthquakes and the rheology of crust and lithosphere. Unfortunately, we are generally unable to answer the above questions. A major

\footnotetext{
Additional supporting information may be found in the online version of this article.

${ }^{1}$ Aix-Marseille Université, CEREGE CNRS-IRD UMR 34, Aix en Provence, France.

${ }^{2}$ GEOAZUR, CNRS, IRD, Observatoire de la Côte d'Azur, Université de Nice Sophia Antipolis, Sophia Antipolis, France.

${ }^{3}$ IPGP, Équipe de Tectonique, Sorbonne Paris Cité, Univeversity Paris Diderot, UMR 7154, CNRS, Paris, France.

${ }^{4}$ Now at Earth and Planetary Science Department, University of California, Berkeley, California, USA.

${ }^{5}$ Géosciences Montpellier UMR CNRS 5243, Université Montpellier Place E. Bataillon, Montpellier, France.
}

Corresponding author: L. C. Benedetti, Aix-Marseille Université CEREGE CNRS-IRD UMR 34, Plateau de l'Arbois, Aix en Provence, 13545, France. (benedetti@cerege.fr)

(C)2013. American Geophysical Union. All Rights Reserved. 2169-9313/13/10.1002/jgrb.50299 reason is that information that precisely describes the distribution of large earthquake occurrence times and slips on a fault is lacking. Instrumental and historical earthquake data provide information on periods that are generally much shorter than the mean recurrence times of large events on faults. Paleoseismological data provide longer records of large earthquakes, but these records are generally still too short to unequivocally document the shape of the distribution of large earthquake occurrence times and slips. Paleoseismological data allow, however, to test the various theoretical models of earthquake occurrence that are proposed. These models are of two types [e.g., Kagan and Jackson, 1991; Sornette and Knopoff, 1997; Faenza et al., 2004]. The first type of model is Poissonian, which assumes that a large earthquake occurs on a fault with no memory of the previous event; large events on faults should thus show a memoryless and hence variable distribution of time intervals and slips [e.g., Sornette and Knopoff, 1997 and references therein]. The second type of model assumes the opposite hypothesis in which the occurrence of a large earthquake on a fault depends, at least partly, on the time of the previous large event. The fundamental support for such time-dependent models is the elastic rebound theory [Reid, 1910]. According to this theory, large earthquakes should repeat on a fault at quasi-periodic times and produce 
fairly similar slips (so-called "characteristic earthquake model" [e.g., Schwartz and Coppersmith, 1994]).

[3] Although available worldwide earthquake data, including paleoseismological data, allow testing these various models, they do not allow yet to discriminate them. On some fault cases, large earthquakes are found to repeat at fairly regular times and produce similar slip amplitudes [McCann et al., 1979; Shimazaki and Nakata, 1980; Schwartz and Coppersmith, 1994; Nishenko and Buland, 1987; Wesnousky, 1994; Sieh, 1984, 1996; Tapponnier et al., 2001; Haibing et al., 2005; Parsons, 2008; Scharer et al., 2010, 2011; Klinger et al., 2011]. These characteristic earthquakes are also suggested to break similar sections of the faults. Yet, in many other fault cases, large earthquakes are found to occur in clusters. A cluster is a group of large earthquakes that occur in a time span considerably shorter than the mean recurrence interval [e.g., McCalpin and Nishenko, 1996]. Earthquake clustering is observed at different timeand space-scales, from $<$ tens of years (e.g., aftershocks sequences [Kagan and Jackson, 1991] and cascade of events on a fault [e.g., Bernard and Zollo, 1989; Amato et al., 1998]) to centuries [Goes, 1996; Pirazzoli et al., 1996; Stiros, 2001; Stein et al., 1997] and millenniums [Wallace, 1987; Grant and Sieh, 1994; Marco et al., 1996; McCalpin and Nishenko, 1996; Rockwell et al., 2000; Holbrook et al., 2006; Ferry et al., 2007, 2011; Dolan et al., 2007; Sieh et al., 2008; Meltzner et al., 2010; Schlagenhauf et al., 2011], on individual faults, and on different faults within a large-scale fault system [e.g., Bucknam et al., 1980; Baljinnyam et al., 1993; Nur and Cline, 2000; Rockwell et al., 2000; Bell et al., 2004; Vanneste et al., 2006; Scholz, 2010]. When multiple faults within a system are found to break in fairly coeval large earthquakes, the clustering is referred to as earthquake synchrony [e.g., Scholz, 2010]. The increasing number of earthquake data worldwide which document clustering of strong events makes a number of authors to suggest that clustering and synchrony of large earthquakes are the way most seismogenic faults release the accumulated stresses and strain [Allen, 1975; Wallace, 1987; Kagan and Jackson, 1991; Rockwell et al., 2000; Scholz, 2010]. However, although the longest available earthquake records are up to 20-50 ka long, they might still be too short to represent a statistically meaningful representation of the event time and slip distribution. One possibility thus exists that the observed periodicity or clustering of large earthquakes is an artifact within a strictly Poissonian distribution [e.g., McCalpin and Nishenko, 1996; Kagan et al., 2012].

[4] The question of how large earthquakes repeat on faults, and within fault systems, is thus still posed and begging more data to test the available models. In the present paper, we provide new paleoseismological data that document the large earthquake record on seven seismogenic faults. The faults belong to the Lazio-Abruzzo normal fault network (LAFN) in central Italy, which has been the site of two historical dramatic earthquakes, the 1915 Avezzano Ms 7 (30,000 casualties [e.g., Boschi et al., 1997]) and the 2009 L'Aquila Mw 6.3 ( $\sim 350$ casualties and current allegation of scientists [Chiarabba et al., 2009]) earthquakes. The LAFN includes more than 20 large seismogenic normal faults (i.e., with length $\geq \sim 10 \mathrm{~km}$ ), and we analyze here seven of them that form a $\sim 30 \mathrm{~km} \times 100 \mathrm{~km}$ large system (Fucino fault system). We collected more than 800 samples in the preserved, seismically exhumed limestone fault scarps, and measured their content of in situ cosmogenically produced ${ }^{36} \mathrm{Cl}$. The methodology based on the use of the ${ }^{36} \mathrm{Cl}$ cosmogenic isotope allows measuring the ages and the surface slips of the most recent large earthquakes that contributed to the fault scarp exhumations, and hence recovering the Holocene exhumation history of the faults. We have pioneered the development and use of this method [Benedetti et al. 2002, 2003; Palumbo et al. 2004; Schlagenhauf et al., 2010, 2011]. This is the first time that the ${ }^{36} \mathrm{Cl}$ method is applied to such a large number of faults and so doing, to a large-scale fault system. A corollary is that it is also the first time that such a large number of samples - about ten times more than any published data - are analyzed for ${ }^{36} \mathrm{Cl}$ content measurement. This dense data collection allows us to recover the number, ages, and slips of the most recent large earthquakes on the seven faults and examine whether these various earthquakes had any temporal or spatial organization on the individual faults and within the entire fault system. We find that such an organization did exist as more than 30 large earthquakes broke the seven faults in specific intervals over the last $\sim 12 \mathrm{ka}$.

\section{Seismotectonics of the Lazio-Abruzzo and Fucino Fault Systems}

\subsection{The Lazio-Abruzzo Fault Network}

[5] The Fucino fault system belongs to the broader LazioAbruzzo fault network (LAFN, inset, Figure 1). About $60 \mathrm{~km}$ wide and $100 \mathrm{~km}$ long, the LAFN is the largest normal fault network in the Apennines. It formed in the Miocene in response to an extensional regime that followed the compressional phase that had generated the prominent carbonate mountains of central Italy [e.g., Bosi, 1975; Benedetti, 1999; Piccardi et al., 1999]. Though some of the LAFN faults have long been recognized [e.g., Bosi, 1975, Piccardi et al., 1999], some have not been sufficiently mapped, and the geometry of the overall fault network has not been described. Therefore, our first step was to identify and map the LAFN faults, and we did so based on the combined analysis of seven pairs of stereoscopic panchromatic SPOT satellite images of 2.5-5 m resolution, numerous aerial photos of about $1 \mathrm{~m}$ resolution, topographic digital elevation models (Shuttle Radar Topography Mission and Advanced Spaceborne Thermal Emission and Reflection Radiometer (ASTER) of 90 and $30 \mathrm{~m}$ resolution, respectively), geological maps [Vezzani and Ghisetti, 1998], and extensive field work. It is now well established that most seismogenic faults can be unambiguously recognized from the trace that they imprint in the surface morphology [e.g., Tapponnier and Molnar, 1977; McCalpin and Nishenko, 1996]. In extensional settings as that of the LAFN, the main indications of recent fault movements are well-preserved, steep, continuous cumulative escarpments, triangular facets shaping the fault escarpments, existence of small, steep scarplets at the base of the cumulative escarpments, fault traces cutting across recent morphological markers [e.g., Wallace, 1977, Armijo et al., 1992]. These characteristic morphological features are observed along most of the LAFN faults, and this allowed us to recognize faults with recent (i.e., late Quaternary) movement, down to faults of $\mathrm{km}$ length scale. These faults are presented in Figure 1. We have mapped with thicker 


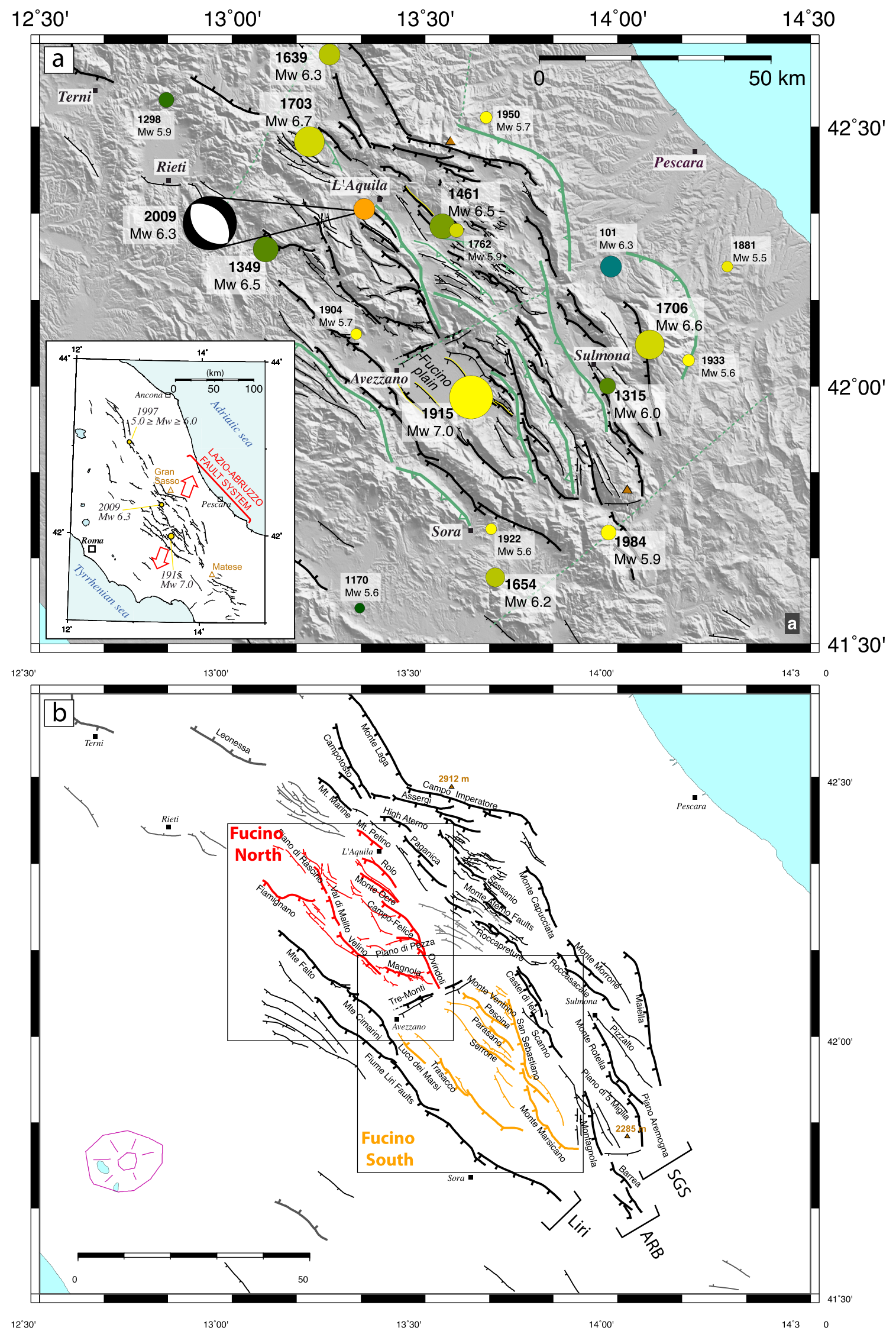

Figure 1 
traces the faults that show either the highest and steepest cumulative escarpments or a small fresh scarplet at the base of their cumulative escarpment. In thinner traces are the secondary faults that we suspect to be active though the morphological evidence is less clear. For clarity, we have simplified the names of the faults compared to many provided in the literature [Galadini and Messina, 1994; Giraudi and Frezzotti, 1995; Salvi and Nardi, 1995; Michetti et al., 1996; Pantosti et al., 1996; Giraudi, 1998; Galadini and Galli, 1999, 2000, Galadini et al., 2003; Piccardi et al., 1999; D'Addezio et al., 2001; Cavinato et al., 2002; Galadini et al., 2003; Salvi et al., 2003; Pizzi and Pugliese, 2004].

[6] The Lazio-Abruzzo fault network is made of a large density of NW to NNW trending, normal faults. These faults organize, however, into four principal, roughly parallel, NW striking, SW dipping systems, from west to east: Liri, Fucino, Aterno-Roccapreturo-Barrea (ARB), and Sulmona-Gran Sasso (SGS) systems. The Liri, ARB, and SGS systems are 80-100 km long, narrow, right stepping en echelon fault zones. They strike NW to NNW overall, but all three systems curve counterclockwise at their northern tip and splay into multiple secondary branches, in a horsetail fashion (see, e.g., Manighetti et al. [2001a] for further details on horsetail faulting). This suggests that the NW trending Liri, ARB, and SGS systems might have a left-lateral component of slip in addition to their dominant normal one.

[7] In between the Liri, ARB, and SGS narrow fault systems extends a broader and more complex fault zone, the Fucino fault system. We describe this system in detail in the following section.

[8] The LAFN has developed in between and superimposed on large, ancient thrust systems (green in Figure 1a), and it is likely that at least the major LAFN normal faults root at depth on thrust interfaces [e.g., Pizzi and Galadini, 2009].

[9] The LAFN has accommodated a $\sim \mathrm{N} 20^{\circ} \mathrm{E}$ extension at a rate of 2-4 mm/yr over the last decade [Hunstad et al., 2003; Nocquet and Calais, 2004; D'Agostino et al., 2001, 2008; Serpelloni et al., 2007], and possibly up to 3-9 mm/ yr over the last $20 \mathrm{ka}$ [Piccardi et al., 1999]. Each of the four major fault systems described above might thus accommodate $0.5-2 \mathrm{~mm} / \mathrm{yr}$ of horizontal extension that might convert into $1-4 \mathrm{~mm} / \mathrm{yr}$ of vertical slip on each system (assuming an average $60^{\circ}$ dip) [Vezzani and Ghisetti, 1998].

[10] Several historical earthquakes of magnitudes up to Mw 7.0 have struck the LAFN over the last 700 years (Figure 1) including the $2009 \mathrm{Mw} 6.3 \mathrm{~L}$ 'Aquila earthquake which broke the northern tip of the ARB fault system (Paganica fault [e.g., Chiarabba et al., 2009; Chiaraluce et al., 2011]). The oldest well-recorded earthquake occurred southeast of Rieti in $1349(\mathrm{I}=\mathrm{IX}-\mathrm{X})$, while the strongest and most destructive event struck the Fucino basin in 1915, destroying the city of Avezzano and most surrounding villages (Avezzano earthquake, 13 January 1915, I XI, $\mathrm{Mw} \sim 7.0,30,000$ casualties, Figures $1 \mathrm{a}$ and 2b) [e.g., Boschi et al., 1997; Gruppo di Lavoro CPTI, 2004].

\subsection{The Fucino Fault System}

[11] The Fucino fault system has both common and distinct features compared with the Liri, ARB, and SGS systems (Figures 1 and 2). Similar to the other systems, it is a $\sim 100 \mathrm{~km}$ long fault zone made of NW to NNW striking, SW dipping normal faults. Most of these faults are segmented in a rightstepping fashion, while they splay to the north in oblique secondary branches. In contrast, the Fucino system is much broader than the other systems and includes several parallel principal fault strands. Also, it is divided into two parts, a northern part, the Fucino north (FN), and a southern part, the Fucino south (FS), by a unique fault, the Tre Monti (TM), that is the only one in the entire region to have an ENE trend. The Fucino system is also the only one to enclose a large $(\sim 30 \mathrm{~km})$ and deep $(\sim 1300 \mathrm{~m})$ basin, the Fucino plain [Cavinato et al., 2002].

[12] The "Fucino north" system includes two parallel NNW trending, W dipping major fault zones, the Fucino northwest (FNW) and the Fucino northeast (FNE) (Figure 2a).

[13] The FNW includes a major fault, the Velino-Magnola (VMF, see Schlagenhauf et al., 2011 for more details), connected to several smaller faults. The VMF is NNW trending, $\sim 45 \mathrm{~km}$ long and divided into four, 10-15 km long, principal fault segments (Magnola, Velino, Val di Malito, and Castiglione). In the north, the VMF is connected to smaller and more easterly striking faults, the major ones are Piano di Rascino ( $10 \mathrm{~km}$ long) and Fiamignano (FI, $\sim 15$ $\mathrm{km}$ long). In the south, the VMF trace curves to the east (Magnola segment). Given $20^{\circ} \mathrm{NE}$ extension [Piccardi et al., 1999], dominant normal motion is expected on the Magnola and Fiamignano fault segments, while more oblique motion, both normal and left lateral, is expected on the NNW striking fault segments. These expectations are in keeping with the highest cumulative vertical throws measured on the Magnola segment ( $~ 800 \mathrm{~m}$ [see Schlagenhauf et al., 2011, Figure 1]) and with the prominent height of the Fiamignano cumulative escarpment $(\sim 450 \mathrm{~m}$, Figure $2 \mathrm{c})$. All in all, the cumulative vertical slip on the FNW fault system decreases quite regularly from south to north [see Schlagenhauf et al., 2011, Figure 1]. Well-preserved scarplets are mainly observed in the southern half of the FNW, and along the Fiamignano fault (Figure 2a and supporting information Figures E1).

[14] The FNE is a $\sim 5 \mathrm{~km}$ long, NNW trending fault zone that is divided into six $\sim 10 \mathrm{~km}$ long, principal fault segments (Ovindoli, Piano di Pezza, Campo Felice, Monte Ocre, Roio, and Monte Petino faults, Figures 1 and $2 b$ ) arranged in a right-stepping echelon, among which the Campo Felice fault (CF) is the largest and the one having the clearest and highest

Figure 1. (a) Seismotectonic map of Lazio-Abruzzo fault system. Normal faults are in black. Shaded relief from $90 \mathrm{~m}$ pixel Shuttle Radar Topography Mission digital elevation model, illuminated from NE. Historical earthquakes epicenters $(\mathrm{Mw} \geq 5.9)$ are from catalog CPTI04 [Gruppo di Lavoro, 2004] covering the period -217 to 2002. Faults that ruptured in 1915 and 2009 earthquakes are underlined in yellow. Major Cenozoic thrusts are indicated in green [Vezzani and Ghisetti, 1998]. Inset: Major active faults in central Italy with extension direction and largest recent earthquakes. (b) Fucino north and Fucino south normal faults systems highlighted in red and orange, respectively. Squares indicate Figures $2 \mathrm{a}$ and $2 \mathrm{~b}$. Thicker traces indicate major faults and/or faults with clearest evidence of recent activity. 

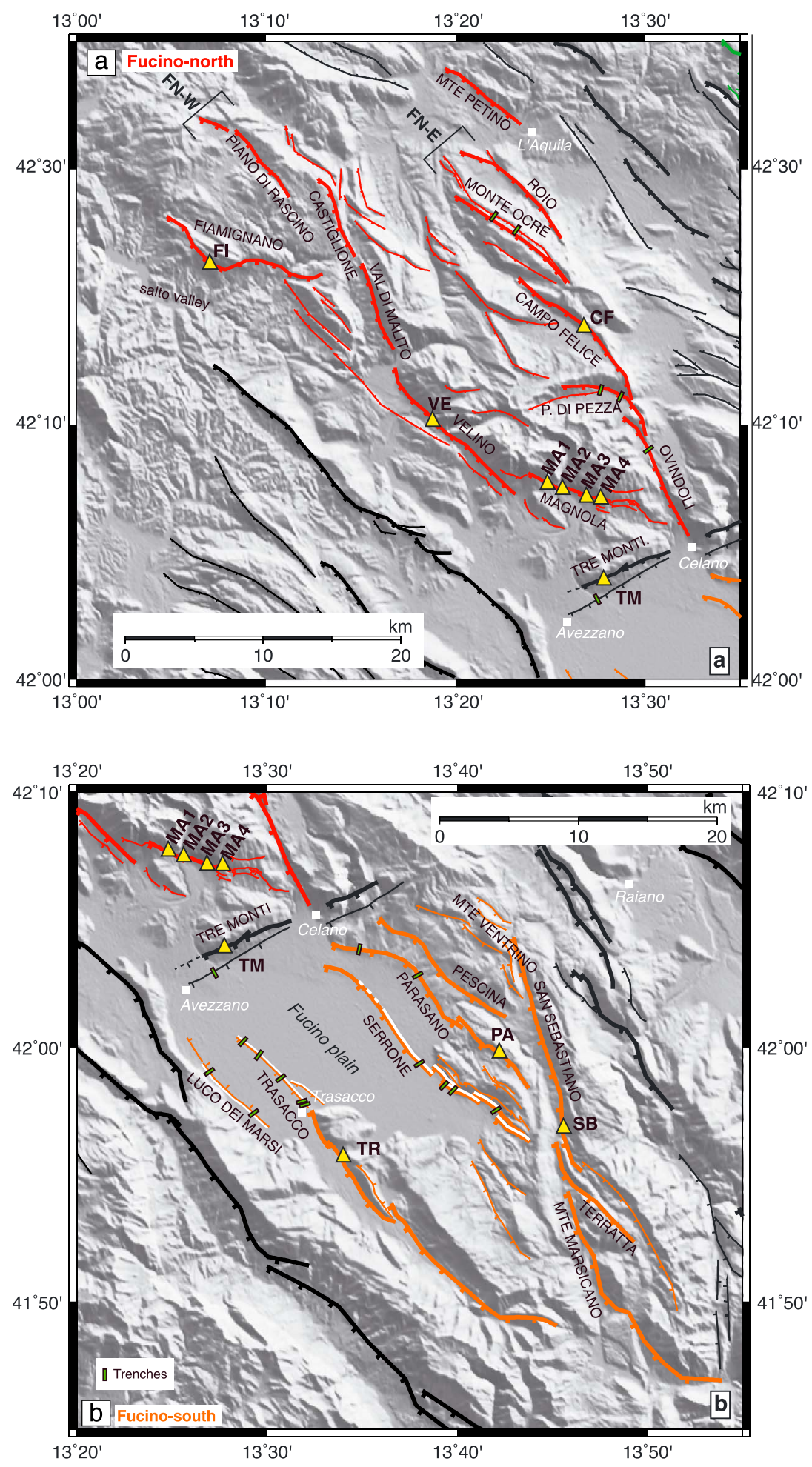

Figure 2. Active normal faults and paleoseismological sites in the (a) Fucino north fault system and (b) Fucino south fault system. Green rectangles show location of trenches and yellow triangles are ${ }^{36} \mathrm{Cl}$ sites discussed in text (see text for references). Faults that ruptured in 1915 are underlined in white. (c) Cumulative displacement versus length profiles measured on each studied fault. The profiles were measured on a digital elevation model with a resolution of $20 \mathrm{~m}$ provided by website SINAnet (http://www.sinanet. isprambiente.it/it). Note that the cumulative slip-length profile of the VMF can be found in Schlagenhauf et al., 2011. All profiles are shown at same length scale, but vertical scale differs among the plots (for clarity). The TR profile could be measured only on the central and eastern segments of the fault. Toward their ends, some fault traces become more subtle to identify, or they connect to nearby faults. This explains why certain slip profiles show still significant slip values at their ends. Yellow triangles indicate the ${ }^{36} \mathrm{Cl}$ sites. 

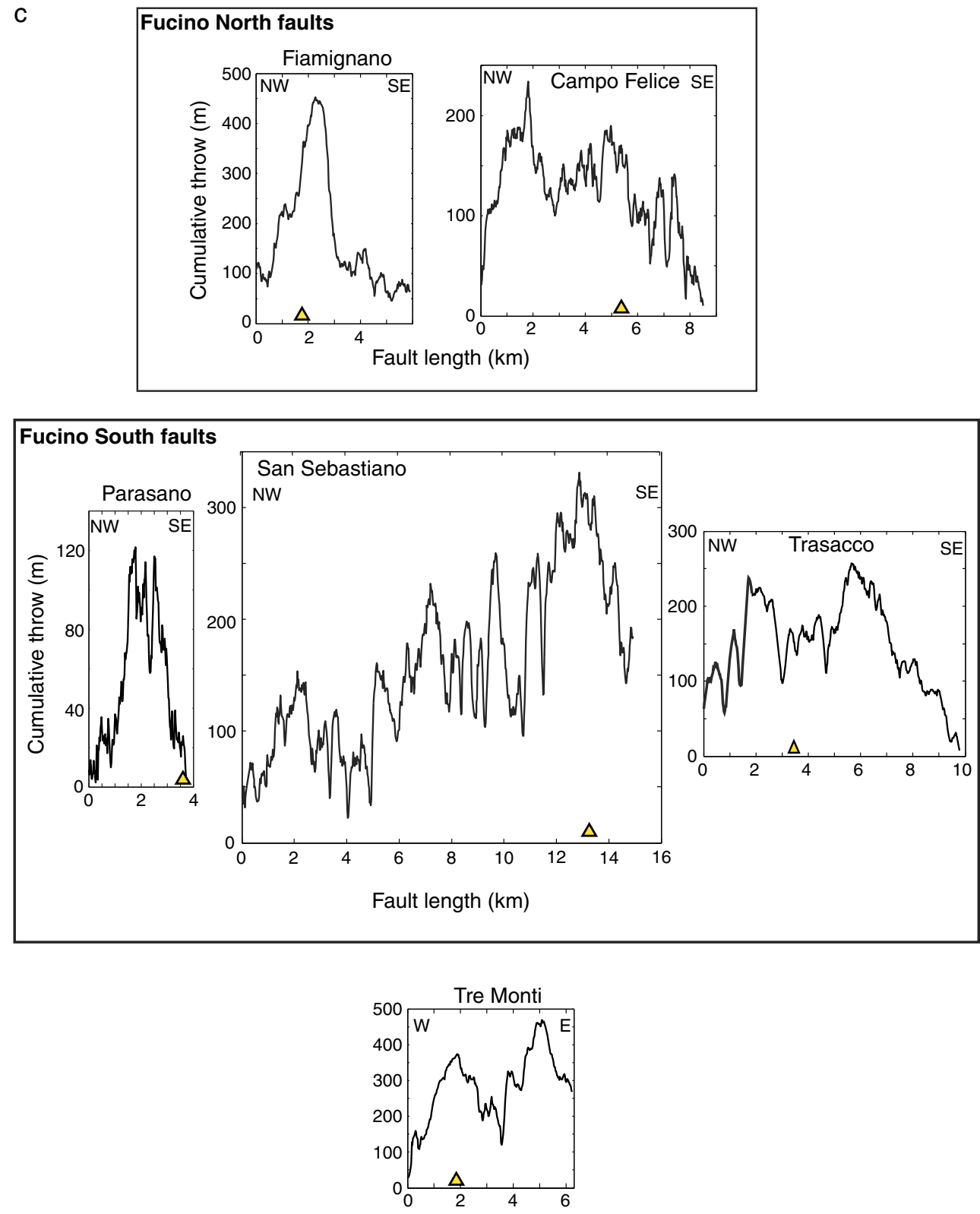

Figure 2. (continued)

cumulative escarpment. CF is thus the major fault segment in the overall FNE system. Most of the FNE segments have their trace slightly curving counterclockwise in the north and splaying into several smaller, more easterly striking faults. Together these suggest that the FNE has an oblique normal and left-lateral motion on its NNW mean strike, while dominant normal slip is expected on its more NW trending sections. The FNE cumulative escarpments are smaller than those of the FNW faults (Figure 2c, 400-800 m for FNW and $\sim 200 \mathrm{~m}$ for FNE). Well-preserved scarplets underline most of the FNE faults, and the Piano di Pezza fault clearly offsets late Quaternary sediments [Pantosti et al., 1996] (supporting information Figure E2).

[15] South of the Tre Monti fault, the "Fucino south" system includes two subparallel NW to NNW trending, $\sim 40 \mathrm{~km}$ long, W dipping major fault zones, the Trasacco fault zone (TR) and the San Sebastiano fault zone (SB) (Figure 2b).
[16] The SB is among the most continuous and longest fault zones of the Fucino south area, and it also has the highest cumulative escarpment ( $350 \mathrm{~m}$, Figure $2 \mathrm{c})$, with a cumulative vertical throw that decreases from south to north. It is made of three principal fault segments, Monte Marsicano, Terratta, and San Sebastiano, that form a rightstepping echelon along the mean NNW strike of the fault zone. The SB fault trace curves counterclockwise at both its northern and southern tips, and hence terminates in a horsetail fashion. The horsetail is particularly developed in the NW quadrant of the fault zone, where it includes four principal NW trending, 10-20 km long, south dipping normal faults, the Monte Ventrino, Pescina, Parasano, and Serrone faults. The overall geometry of the SB fault zone thus suggests that its slip is both normal and left lateral on its principal NNW strand, while dominant normal motion is expected on its secondary NW trending horsetail faults. 
Table 1. Available Data Documenting the Past Earthquakes on the FN and FS Faults ${ }^{\mathrm{a}}$

\begin{tabular}{|c|c|c|c|}
\hline Ruptured Fault ${ }^{\mathrm{b}}$ & Earthquake Age & Measured Coseismic Slip & Remarks on Age and Slip Determination \\
\hline \multirow[t]{2}{*}{ Monte Ocre (5) } & $0.6-3.7 \mathrm{ka}$ & $0.3-0.5 \mathrm{~m}$ & \multirow[t]{2}{*}{$\begin{array}{l}\text { Large range of ages because no clear correlation of } \\
\text { events between the two trenching sites }\end{array}$} \\
\hline & $\begin{array}{l}\text { two events in } \\
0.6-7.6 \mathrm{ka}\end{array}$ & each $0.3-0.5 \mathrm{~m}$ & \\
\hline \multirow[t]{3}{*}{ Ovindoli-Pezza (2) } & $<1$ ka & $\sim 3 \mathbf{m}$ & $\begin{array}{l}\text { Event seen at three trenches; preearthquake paleosoil dated with } \\
\text { several radiocarbon dates; slip well determined from trench reconstruction }\end{array}$ \\
\hline & 3-4 ka & $\sim 2.5 \mathrm{~m}$ & $\begin{array}{l}\text { Event seen in five trenches; age constrained by several radiocarbon dates; } \\
\text { slip well estimated from trench reconstruction }\end{array}$ \\
\hline & $>7 \mathrm{ka}$ & not constrained & $\begin{array}{c}\text { Event seen at one trench only; predates a paleosoil dated with few } \\
\text { radiocarbon data. }\end{array}$ \\
\hline \multirow[t]{4}{*}{ Serrone $(1,3,4)$} & $1915 \mathrm{AD}$ & $0.3-0.6 \mathrm{~m}$ & 1915 event observed in four trenches \\
\hline & $<1.4$ ka BP & $>0.3 \mathrm{~m}$ & Age inferred from one radiocarbon date; slip poorly constrained \\
\hline & $\sim 2.3-2.9 \mathrm{ka}$ & not constrained & $\begin{array}{l}\text { No figure in the paper concerning this event; ages are based on one } \\
\text { thermoluminescence date only and archeological considerations }\end{array}$ \\
\hline & $7.1-10.4$ ka BP & $2-3 \mathrm{~m}$ & Slip not well constrained; age bounded by two radiocarbon dates \\
\hline \multirow[t]{2}{*}{ Parasano (4) } & $<4.5 \mathrm{ka}$ & $\sim 1 \mathrm{~m}$ & $\begin{array}{l}\text { - No rupture attributed to } 1915 \text { - Age inferred from archeological } \\
\text { remains in upper soil (no absolute dating) }\end{array}$ \\
\hline & $\begin{array}{l}\text { three events in } \\
4.5-20 \mathrm{ka}\end{array}$ & not constrained & Age inferred from one radiocarbon age \\
\hline \multirow[t]{5}{*}{ Trasacco NW (4) } & 1915 AD & $0.1-0.7 \mathrm{~m}$ & 1915 event observed in four trenches \\
\hline & $<2$ ka & $0.2-0.7 \mathrm{~m}$ & Offset of a Roman Aqueduc \\
\hline & $\sim 3.5 \mathrm{ka}$ & not constrained & $\begin{array}{l}\text { Event detection based on unconformities between soil levels; No absolute } \\
\text { dating but ages inferred from correlation with Fucino basin stratigraphy }\end{array}$ \\
\hline & $8.0-12.7 \mathrm{ka}$ & & \\
\hline & After 12.0 & & \\
\hline
\end{tabular}

\footnotetext{
${ }^{\mathrm{a}}$ Bold ages are events that are considered well constrained and thus displayed on Figure 5 .

${ }^{\mathrm{b}}$ From published records based on trenches. Sources are indicated by the number in parentheses: 1, Michetti et al. [1996]; 2, Pantosti et al. [1996]; 3, Boschi et al. [1997]; 4, Galadini and Galli [1999, and references therein]; 5, Salvi et al. [2003].
}

These expectations are in keeping with the high escarpments of the Monte Ventrino, East Parasano, and East Serrone faults. Furthermore, the cumulative vertical throws of the Parasano and Serrone faults might be greater than observed at the surface as parts of their escarpments are presently hidden under the thick Fucino sediments; the total vertical displacement on the Serrone fault might actually be greater than $1100 \mathrm{~m}$ [Cavinato et al., 2002]. A fresh, $\sim 9$ and 4-5 m high, limestone scarplet underlines the central part of the SB strand and the Parasano secondary fault, respectively.
[17] The Trasacco fault extends over $\sim 35 \mathrm{~km}$ long at the other side of the Fucino plain. It strikes NW overall, and shows a simple geometry with three principal, $\sim 10 \mathrm{~km}$ long, disconnected fault segments. The two southernmost segments have wellexpressed cumulative escarpments, whose height decreases overall from south to north. In contrast, the northernmost segment forms no clear topographic escarpment; its existence in the Fucino plain was revealed by its rupturing in the 1915 earthquake (Figure 2b). If the TR fault is similar to the other NW trending faults of the Fucino region, it may have a

Table 2. Geometrical Characteristics of ${ }^{36} \mathrm{Cl}$ Sites

\begin{tabular}{|c|c|c|c|c|c|c|c|c|c|c|c|c|c|}
\hline Fault & Site & $\rho_{\text {rock }}$ & $\rho_{\text {coll }}$ & $\alpha$ & $\beta$ & $\gamma$ & $\begin{array}{c}\text { Scarp } \\
\text { Height H (m) }\end{array}$ & $\begin{array}{c}\text { Elevation } \\
( \pm 5 \mathrm{~m})\end{array}$ & Latitude & Longitude & $\begin{array}{c}\mathrm{EL}_{-} \mathrm{f} \\
\text { Stone } 2000\end{array}$ & $\begin{array}{c}\text { EL_mu } \\
\text { Stone } 2000\end{array}$ & $\begin{array}{c}\text { Sampling } \\
\text { Height (m) }\end{array}$ \\
\hline Fiamignano & FI & 2.68 & 1.5 & $12^{\circ}$ & $40^{\circ}$ & $38^{\circ}$ & 20 & $1178 \mathrm{~m}$ & $\mathrm{~N} 42.2720$ & E013.1161 & 2.597 & 1.648 & 7.1 \\
\hline Campo Felice & CF & 2.66 & 1.5 & $30^{\circ}$ & $55^{\circ}$ & $45^{\circ}$ & 17 & $1595 \mathrm{~m}$ & $\mathrm{~N} 42.2283$ & E013.4437 & 3.558 & 1.974 & 8.8 \\
\hline Magnola & MA1 $^{\text {a }}$ & 2.67 & 1.5 & $25^{\circ}$ & $40^{\circ}$ & $35^{\circ}$ & 15 & $1265 \mathrm{~m}$ & N42.1280 & E013.4137 & 2.771 & 1.711 & 8.1 \\
\hline Magnola & MA2 $^{\mathrm{a}}$ & 2.67 & 1.5 & $35^{\circ}$ & $50^{\circ}$ & $35^{\circ}$ & 8.6 & $1200 \mathrm{~m}$ & $\mathrm{~N} 42.1240$ & E013.4273 & 2.636 & 1.662 & 8.5 \\
\hline Magnola & $\mathbf{M A 3}^{\mathrm{a}}$ & 2.7 & 1.5 & $30^{\circ}$ & $45^{\circ}$ & $30^{\circ}$ & 20 & $1255 \mathrm{~m}$ & N42.1190 & E013.4480 & 2.750 & 1.703 & 10.1 \\
\hline Magnola & MA4 ${ }^{\mathrm{a}}$ & 2.64 & 1.5 & $30^{\circ}$ & $42^{\circ}$ & $30^{\circ}$ & 7 & $1300 \mathrm{~m}$ & N42.1184 & E013.4613 & 2.846 & 1.737 & 7.0 \\
\hline Velino & $\mathbf{V E}^{\mathrm{a}}$ & 2.71 & 1.5 & $30^{\circ}$ & $40^{\circ}$ & $35^{\circ}$ & 9.5 & $1014 \mathrm{~m}$ & $\mathrm{~N} 42.1685$ & E013.3130 & 2.281 & 1.531 & 7.0 \\
\hline Tre Monti & TM & 2.67 & 1.5 & $20^{\circ}$ & $72^{\circ}$ & $35^{\circ}$ & 3.5 & $970 \mathrm{~m}$ & N42.0650 & E013.4627 & 2.200 & 1.499 & 2.7 \\
\hline Trasacco & TR & 2.64 & 2.6 & $25^{\circ}$ & $65^{\circ}$ & $25^{\circ}$ & 4.7 & $800 \mathrm{~m}$ & N41.9280 & E013.5670 & 1.916 & 1.386 & 4.4 \\
\hline Parasano & PA & 2.64 & 1.5 & $25^{\circ}$ & $55^{\circ}$ & $40^{\circ}$ & 4.0 & $1270 \mathrm{~m}$ & N41.9961 & E013.7027 & 2.777 & 1.713 & 3.3 \\
\hline San Sebastiano & SB & 2.62 & 1.5 & $25^{\circ}$ & $62^{\circ}$ & $50^{\circ}$ & 4.5 & $1214 \mathrm{~m}$ & N41.9466 & E013.7618 & 2.658 & 1.671 & 4.5 \\
\hline
\end{tabular}

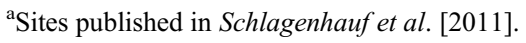


dominant normal motion. The central segment of the TR fault is underlined by a $5 \mathrm{~m}$ high, fresh scarplet.

[18] The northwestern part of the FS system ruptured during the devastating 1915 Avezzano earthquake (Figure 2b). Evidence for surface ruptures were firmly reported on the Serrone, Trasacco (western segment), and Luco dei Marsi faults (Table 1) [Oddone, 1915; Michetti et al., 1996; Galadini and Galli, 1999]. The Avezzano earthquake likely initiated on and mainly broke one of these faults at depth, with this dominant breaking inducing shallow slip distributed on the nearby faults [Galadini and Galli, 1999; see similar case in Jacques et al., 2011]. The total vertical coseismic slip across all traces was estimated to be $1-3 \mathrm{~m}$.

[19] The Tre Monti fault (TM), about $20 \mathrm{~km}$ long, southeast dipping, is the only ENE-WSW-oriented fault in the LAFN. It separates the FN and FS systems, in that the major faults of these two systems end near the Tre Monti fault and do not continue beyond its trace. It forms a $450 \mathrm{~m}$ high cumulative escarpment. Seismic profiles across the Tre Monti fault suggest that it might have a cumulative throw of $\sim 800 \mathrm{~m}$ [Cavinato et al., 2002]. In more detail, the TM fault is made of two principal segments extending on either side of the Celano village, and two parallel, smaller, closely spaced faults (Figure 2b). The two major segments have a $\sim 5 \mathrm{~m}$ high wellpreserved scarplet, and the western segment clearly offsets recent lacustrine deposits [Pizzi and Pugliese, 2004].

[20] Most Fucino faults have a cumulative slip versus length profile that is asymmetric and roughly triangular in overall shape (Figure 2c). These specific slip distributions have been shown to typify faults that are both active and propagating laterally in the direction of slip decrease [Manighetti et al., 2001a, 2001b, 2009; Schlagenhauf et al., 2008]. We infer that the VMF [Schlagenhauf et al., 2011, Figure 1], SB, and PA faults are propagating northward (over multiple seismic cycles, see discussion in Manighetti et al., 2005], while the FI and CF faults are propagating southward. The TM fault has a more elliptical slip profile and hence might not be propagating laterally [Manighetti et al., 2001a, 2001b; Schlagenhauf et al., 2008].

[21] To summarize, the Fucino fault system includes four major faults, two in the north, VMF and FNE (well represented by its largest CF fault), and two in the south, SB and TR. These four largest faults are connected to several smaller oblique faults. In the following, we study the four major faults, and three smaller faults, Fiamignano (FI) which is connected to the master VMF fault, Parasano (PA) which is connected to the master SB fault, and Tre Monti (TM) which separates the FN and FS systems. Doing so, we analyze the most important faults of the Fucino region.

\section{3. ${ }^{36} \mathrm{Cl}$ Analysis: Sites, Modeling, and Derived Exhumation Events}

[22] Over the last 10 years, in situ ${ }^{36} \mathrm{Cl}$ has been used to recover the Holocene seismic history of normal faults in the Mediterranean [Gran Mitchell et al., 2001; Benedetti et al., 2002, 2003; Palumbo et al., 2004; Schlagenhauf et al., 2010, 2011]. Large earthquake events that expose previously buried limestone can be dated from the in situ-produced ${ }^{36} \mathrm{Cl}$ concentrations that have accumulated in the exposed fault scarp rocks and the slips they produced at the surface can be measured.

\subsection{Sampling and Modeling}

[23] We have recently developed an improved modeling procedure to analyze ${ }^{36} \mathrm{Cl}$ concentrations in seismically exhumed limestone fault scarp rocks [Schlagenhauf et al., 2010], and we thus use this procedure to analyze the earthquake history of the Fucino system. We refer readers to Schlagenhauf et al. [2010] for details on the code.

[24] The sampling consists in peeling off $\sim 3 \mathrm{~cm}$ of the exposed scarp rocks, every $10 \mathrm{~cm}$, in a continuous fashion from the top to the base of the scarp, along a line parallel to the assumed slip vector. Sampling sites were selected on well-preserved fault scarps at significant distance from any degradation features (such as gullies, colluvial deposits, etc.) (Figures E1 to E6). Wherever possible, sampling was performed on the section of the fault showing the highest cumulative displacement.

[25] The samples were crushed, sieved, and chemically prepared to precipitate $\mathrm{AgCl}$ [Stone et al., 1996; Schlagenhauf et al., 2010]. ${ }^{36} \mathrm{Cl}$ and $\mathrm{Cl}$ concentrations were determined by isotope dilution accelerator mass spectrometry at both CAMS-LLNL (USA) and ASTER-CEREGE (France) and were both normalized to a ${ }^{36} \mathrm{Cl}$ standard prepared by $\mathrm{K}$. Nishiizumi [Sharma et al., 1990]. Replicates measured at both facilities agreed within 5\%, which showed that no additional uncertainties resulted from the change in apparatus. The samples were found to contain $10^{6}-10^{7}$ atoms of ${ }^{36} \mathrm{Cl}$ and $10^{18}-10^{19}$ atoms of $\mathrm{Cl}$, about 100 times more than the blanks that we used. [Cl] concentrations were $<20$ ppm (Suppl. Tables S2), which suggests that the ${ }^{36} \mathrm{Cl}$ production pathways are about $90 \%$ from $\mathrm{Ca}$ spallation, $8 \%$ from slow negative muons capture, and less than $2 \%$ from thermal and epithermal neutrons capture [Schimmelpfennig et al., 2009].

[26] The samples exposed by each slip event originate from below colluvium or a colluvial wedge. Their ${ }^{36} \mathrm{Cl}$ abundance is thus impacted by their preexposure history. The ${ }^{36} \mathrm{Cl}$ concentration profile of a fault section buried under a colluvium is a depth-dependent exponential [e.g., Phillips et al., 2001]. As a large earthquake occurs, the newly exposed scarp section starts accumulating ${ }^{36} \mathrm{Cl}$ at a constant rate. The ${ }^{36} \mathrm{Cl}$ concentration along the exposed scarp section is thus the sum of the ${ }^{36} \mathrm{Cl}$ produced below the surface prior to the earthquake exhumation, and of the ${ }^{36} \mathrm{Cl}$ accumulated at the surface once exposed by the earthquake. Thus, as large earthquakes repeat on a normal fault and exhume deeper portions of its plane, the ${ }^{36} \mathrm{Cl}$ concentration profile along its exposed scarp becomes made of a series of exponential sections separated by discontinuities, horizontal shifts when plotted against scarp height. Those discontinuities reflect each major earthquake or sudden slip event that produced surface slip. When discrete discontinuities can be identified, this identification allows recognition of the different large earthquakes and of the slip they produced at surface, while modeling of the exponential sections allows determination of their age. Theoretical calculations suggest that surface slips lower than $\sim 25 \mathrm{~cm}$ and earthquake ages differing by less than a few 100 years cannot be resolved in the ${ }^{36} \mathrm{Cl}$ modeling [Schlagenhauf et al., 2010]. These limitations imply that the number of earthquakes recovered with the ${ }^{36} \mathrm{Cl}$ approach always is a minimum, as some events can actually be clusters of small and/or roughly synchronous events. 
a
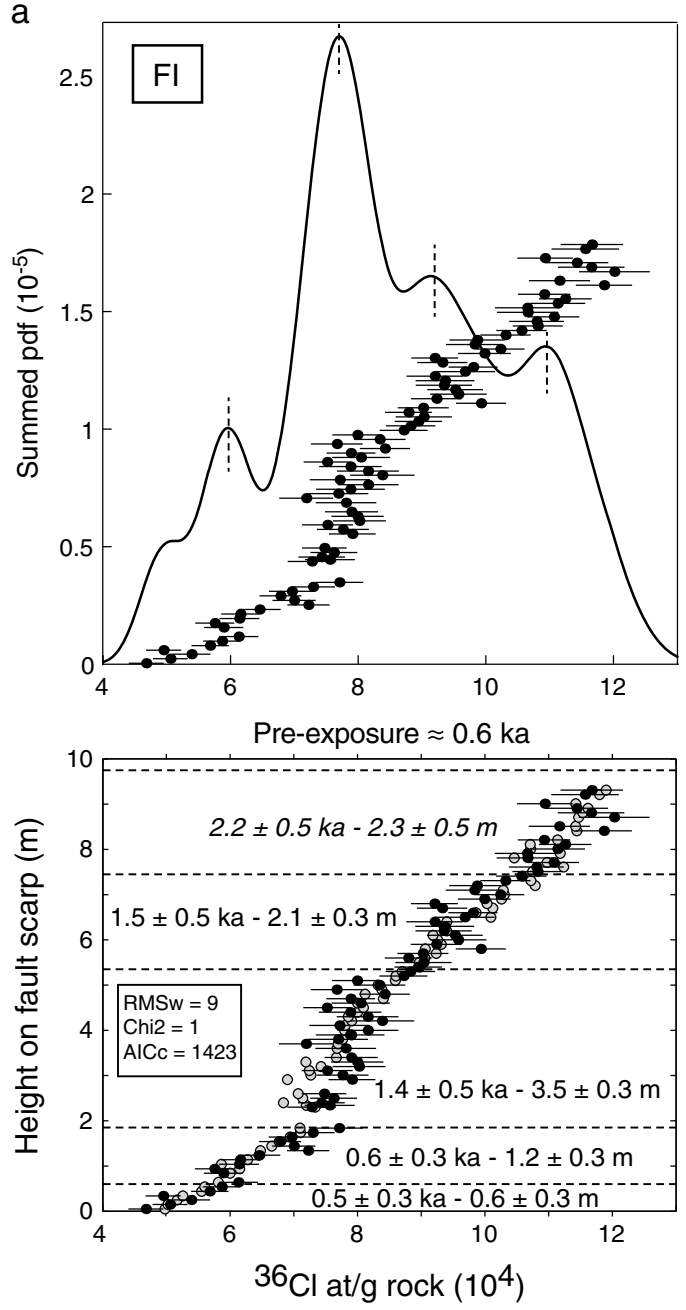

b
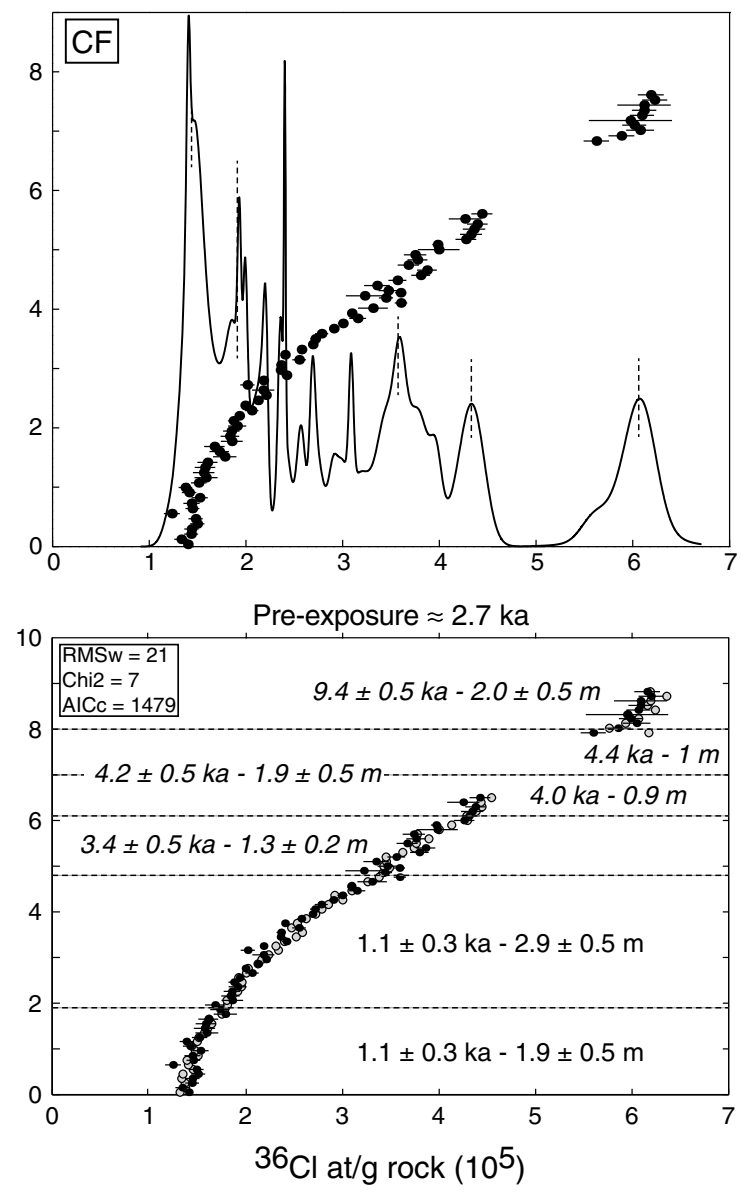

Figure 3. (a) ${ }^{36} \mathrm{Cl}$ data versus scarp height and modeling at site FIa. Top graph is the ${ }^{36} \mathrm{Cl}$ concentration (dots) with the associated probability density function (PDF) that exhibits four discontinuities besides the scarp base, indicated with vertical dotted lines. Bottom graph shows the ${ }^{36} \mathrm{Cl}$ concentrations (black) and the modeled ${ }^{36} \mathrm{Cl}$ concentrations (grey) with inferred ages and slips of events. Error bars are AMS $2 \sigma$ normalized uncertainties. The fitting parameters of the model are indicated in the inset box. Alternative models with more discontinuities are presented in Figure E8 in the supporting information. Those more complex models are less well supported by the data. (b) Same as Figure 3 for site CF. Four meaningful discontinuities besides the base of the scarp are shown in the profile (see text for further details). Alternative models with more discontinuities are presented in Figure E9 in the supporting information. Those more complex models are less well supported by the data. (c) Same as Figure 3 for site SB. Five meaningful discontinuities are visible in the profile, indicated with vertical dotted lines (see text for further details). Alternative models with more discontinuities are presented in Figure E10 in the supporting information. Those more complex models are less well supported by the data. (d) Same as Figure 3 for site PA. Four meaningful discontinuities are visible in the profile, indicated with vertical dotted lines (see text for further details). Alternative models with more discontinuities and with a 1915 slip are presented in Figure E11 in the supporting information. Those more complex models are less well supported by the data. (e) Same as Figure 3 for site TR. Five meaningful discontinuities are visible in the profile, indicated with vertical dotted lines (see text for further details). Alternative models with more discontinuities are presented in Figure E12 in the supporting information. Those more complex models are less well supported by the data. However, a model with a 1915 slip instead of a $3 \pm 0.5 \mathrm{ka}$ event is possible (similar fitting metrics). (f) Same as Figure 3 for site TM. Four meaningful discontinuities are visible in the profile, indicated with vertical dotted lines (see text for further details). Alternative models with more discontinuities, including a 1915 slip, are presented in Figure E13 in the supporting information. Those more complex models are less well supported by the data.

[27] In the following, as suggested in Schlagenhauf et al. [2010], colluvium is the colluvial wedge (with a mean dip $\alpha$ and a density $\left.\rho_{\text {coll }}\right)$ that shields the subterranean fault plane. The exposed scarp has a constant $\operatorname{dip} \beta$, an along-scarp height $H$, and its exposed rocks have a density $\rho_{\text {rock }}$. The upper part of the scarp is referred to as the upper eroded scarp, having a mean dip $\gamma$. Those parameters, along with the latitude, longitude, elevation, and average total ${ }^{36} \mathrm{Cl}$ production rate at surface are reported in Table 2 for each sampling site. The chemical compositions of the rock samples are reported in Tables S1 and S2 in supporting information. Because the colluvium looks roughly similar at all sites but Trasacco, 
C
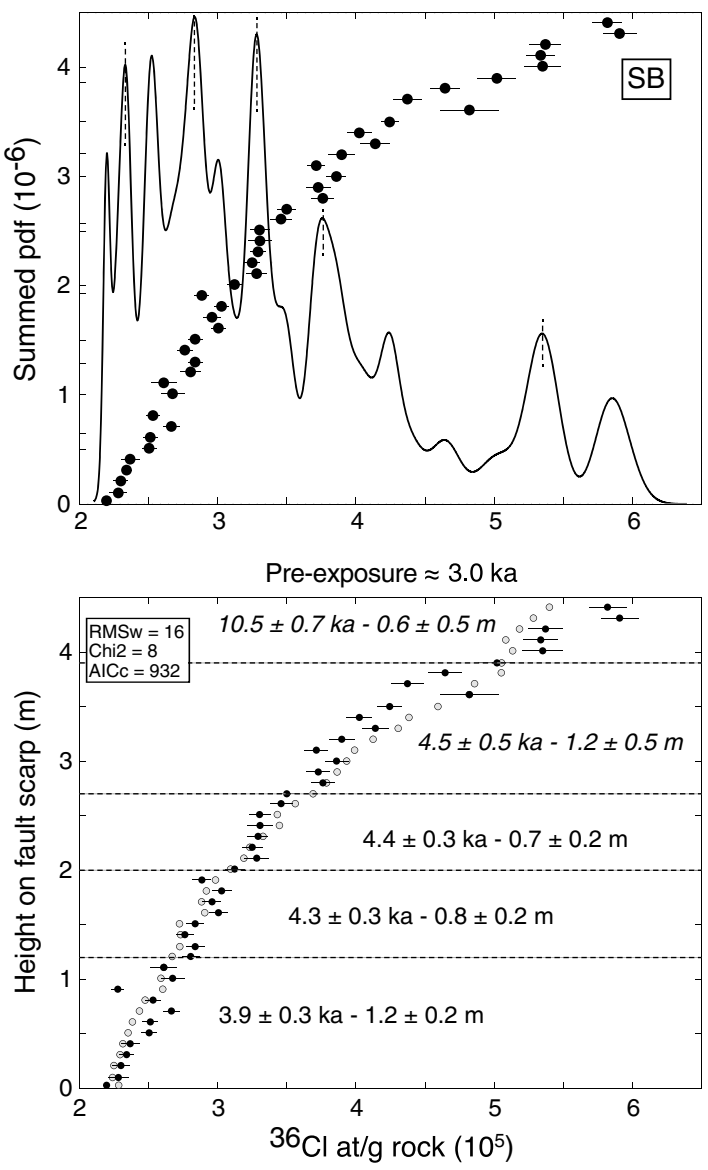

d
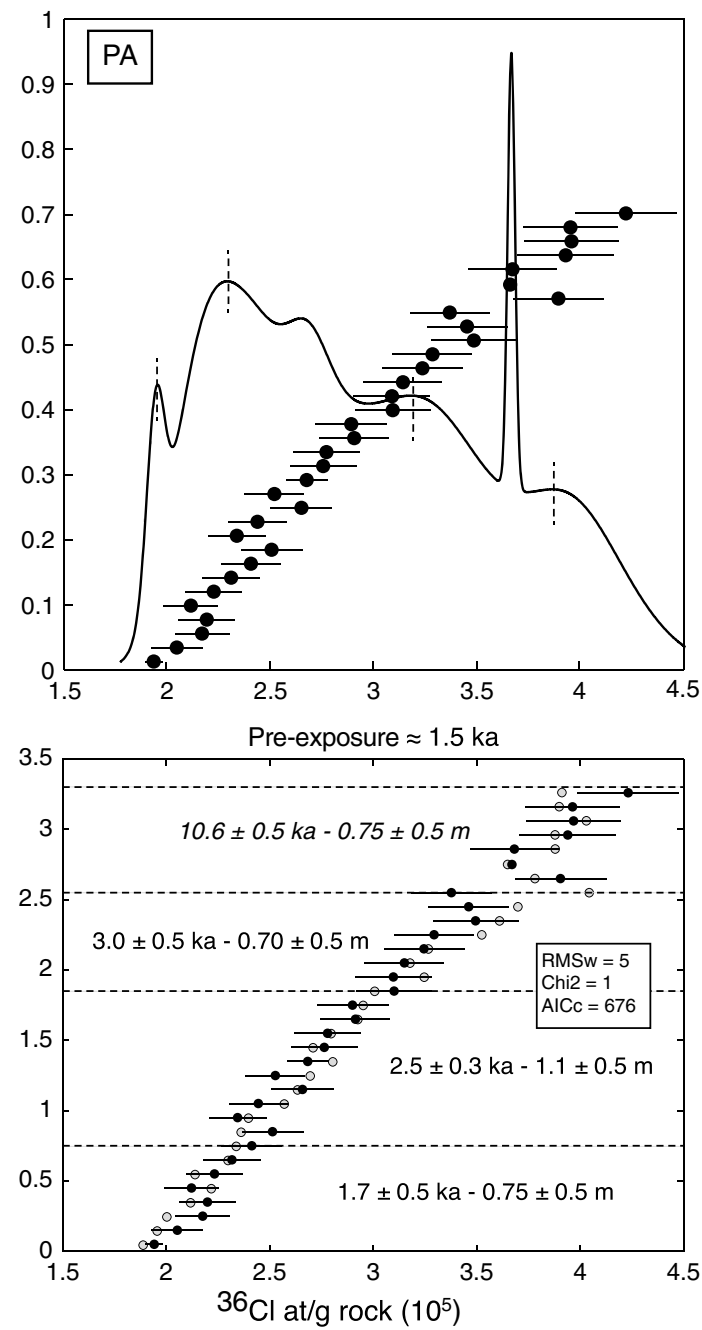

Figure 3. (continued)

we model them with the colluvium mass density determined by Schlagenhauf et al. [2010] at the Magnola site (1.5 g/ $\mathrm{cm}^{3}$ ). At Trasacco, where more indurated colluvium is observed, we model the colluvial wedge with a $2.6 \mathrm{~g} / \mathrm{cm}^{3}$ mass density. The colluvium chemical compositions are approximated by those of the scarp rocks.

[28] The elementary ${ }^{36} \mathrm{Cl}$ production rate from spallation of calcium has been calibrated at a site in Sicily whose latitude, elevation, and exposure duration are similar to those of our sites [Schimmelpfennig et al., 2011]. We thus use this rate, of $42.2 \pm 4.8$ at. of ${ }^{36} \mathrm{Cl} \mathrm{gram}^{-1}$ of $\mathrm{Ca}^{-\mathrm{yr}^{-1}}$, in the following.

[29] Since Schlagenhauf et al. [2010] have shown that the variations of the geomagnetic field are negligible at the latitudes and over the period that we consider, we apply the latitudinal and altitudinal scaling at constant geomagnetic field using the formula of Stone [2000] (Table S3 in supporting information).

[30] The analyzed fault scarp surfaces show no evidence of significant erosion (Figures E1 to E6 in ES) and some of them even show fresh slickensides [e.g., Piccardi et al., 1999]. The scarplets are thus well preserved, what allows us to neglect denudation over their height.
[31] To identify the major discontinuities that shape a $\left[{ }^{36} \mathrm{Cl}\right]-$ profile, we use the summed Probability Density Function (PDF) statistical method [Lowell, 1995, Ludwig, 2003]. The PDF approach represents each measurement as a Gaussian whose $2 \sigma$-width is its analytical uncertainty. The summed PDF curve stacks these individual Gaussians and hence shows pronounced peaks at the concentrations most represented in the data. The most pronounced peaks generally arise from the similar concentrations that mark the discontinuities that we seek. Some smaller and/or more subtle peaks might result, however, from noise or artifacts in the measurements or from very small uncertainties on a few measurements (see discussion in Schlagenhauf et al. $[2010,2011])$. To model the data, we perform the following steps.

[32] We first retain the major and unambiguous PDF peaks only (visual discrimination in a first step) and consider that the major discontinuities that these major peaks reveal coincide with the major exhumation events that we seek. Additionally, the scarp base is the lower limit of the most recently exhumed fault section. This first-step identification of the major discontinuities allows determining the slip of the most obvious exhumation events. 
e
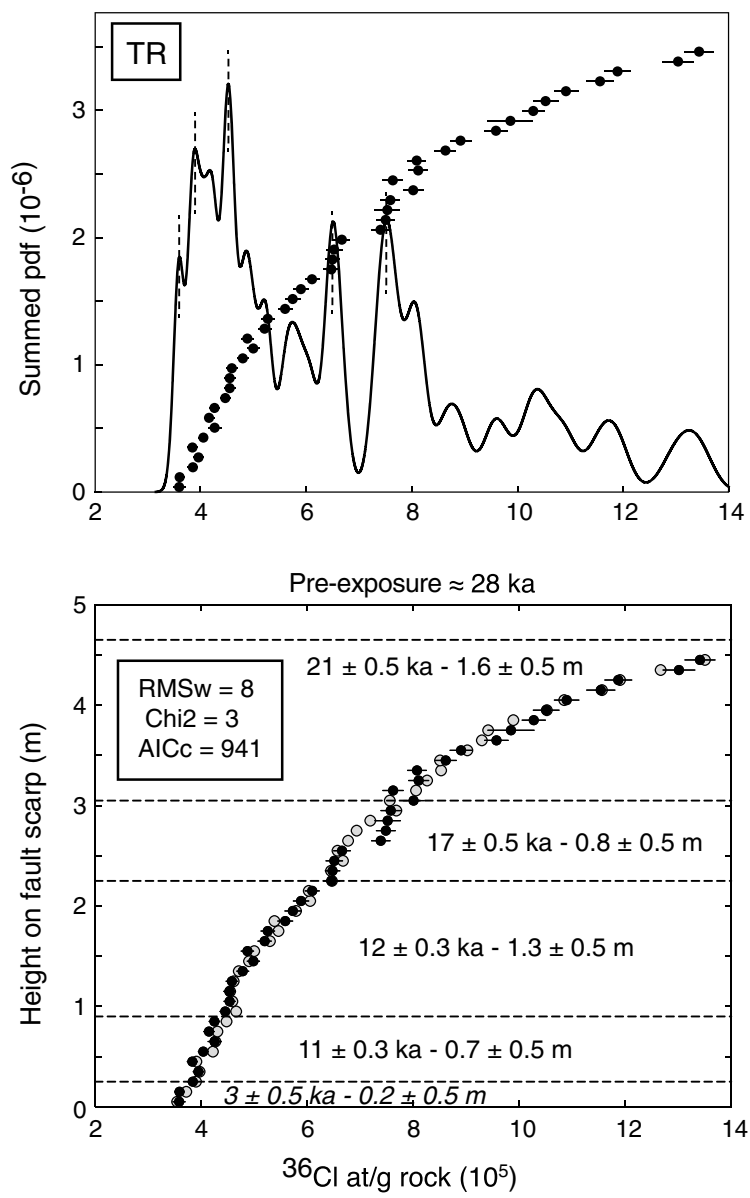

f
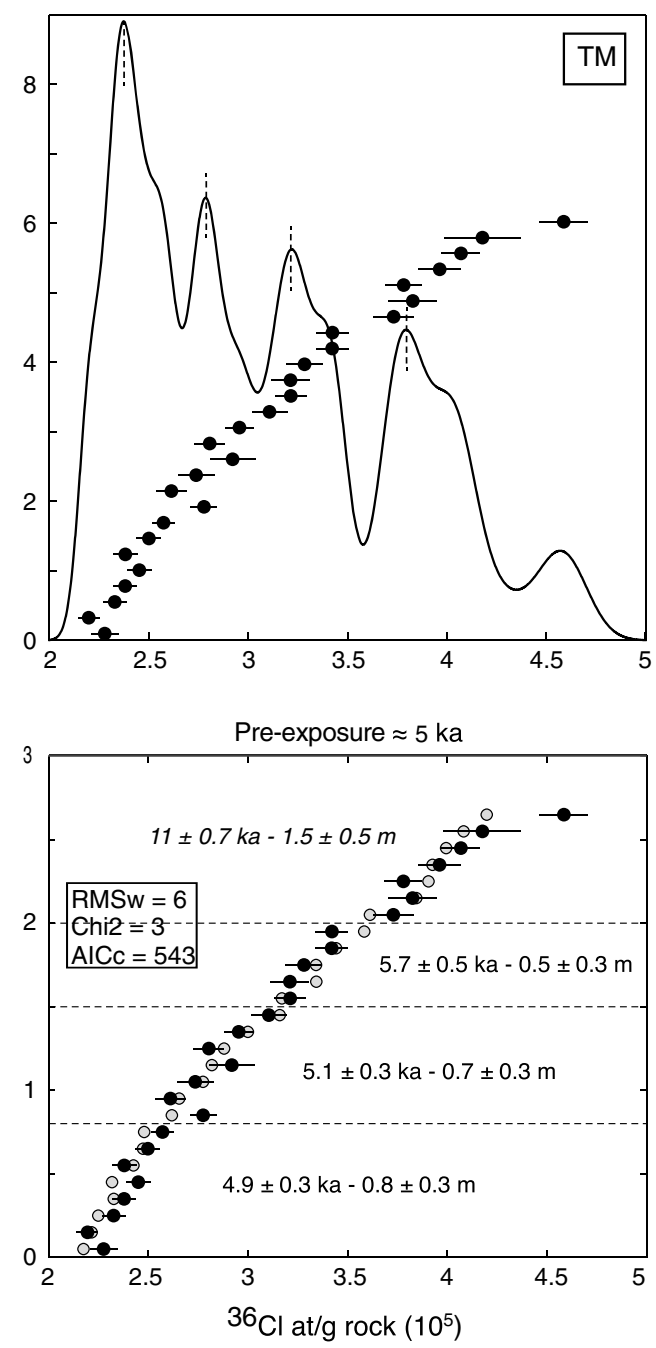

Figure 3. (continued)

[33] Second, we determine the age of each exhumation event by modeling the ${ }^{36} \mathrm{Cl}$ data with the code provided by Schlagenhauf et al. [2010]. The protocol calculates the theoretical $\left[{ }^{36} \mathrm{Cl}\right]$ profile that would result on the scarp given a slip exhumation scenario, parameterized by the number and the displacement of the events as inferred above, a preexposure duration of the samples (see below), and an age for each event. This theoretical profile is then compared to the measured $\left[{ }^{36} \mathrm{Cl}\right]$ profile to assess the likelihood of the tested earthquake scenario. The most likely exhumation scenario is identified by the minimum difference between the modeled and the measured concentration profiles, quantified with three complementary metrics: (i) the weighted root mean square (RMSw) which allows quantifying the fit between modeled and measured concentrations while taking into account the uncertainties on the measurements; (ii) the Chi-square (Chi2) which quantifies the balance between the model improvement and the number of free parameters that contribute to that improvement; and (iii) the Akaike Information Criterion (AICc) [Akaike, 1974], which also measures the balance between the model improvement and the number of introduced free parameters. In a population of tested scenarios, the most robust is the one having the lowest RMSw, Chi2, and AICc values.
[34] A last step consists in introducing additional discontinuities in any model where such additional features might be plausible (i.e., where smaller and/or more subtle PDF peaks are suggested).

[35] The different models possibly suggested at one site are eventually discriminated from their RMSw, Chi2, and AICc values.

[36] As shown by Schlagenhauf et al. [2010], there are several sources of uncertainty that may affect the modeled ages and slips. These include the analytical uncertainties on the measurements of the various chemical elements, on the site geometry (i.e., dip of the colluvium and scarp), on rock and colluvium densities, and on elementary ${ }^{36} \mathrm{Cl}$ production rates. All those uncertainties are epistemic and are not dependent on the chosen model. In the present study, we assess fairly well $(<1-5 \%)$ the level of uncertainty in all these parameters but the elementary production rates. Uncertainties on the elementary production rates are estimated at present to be 5-10\% [e.g., Schimmelpfennig et al., 2011].

[37] An additional source of inaccuracy in the modeled ages is the preexposure duration. The preexposure is the history of the scarp before the top scarp was exposed. Evidently, we have no means to know it. Yet, the preexposure duration tightly 
Table 3. Ages and Slips of All Events Recovered in Present Study ${ }^{\mathrm{a}}$

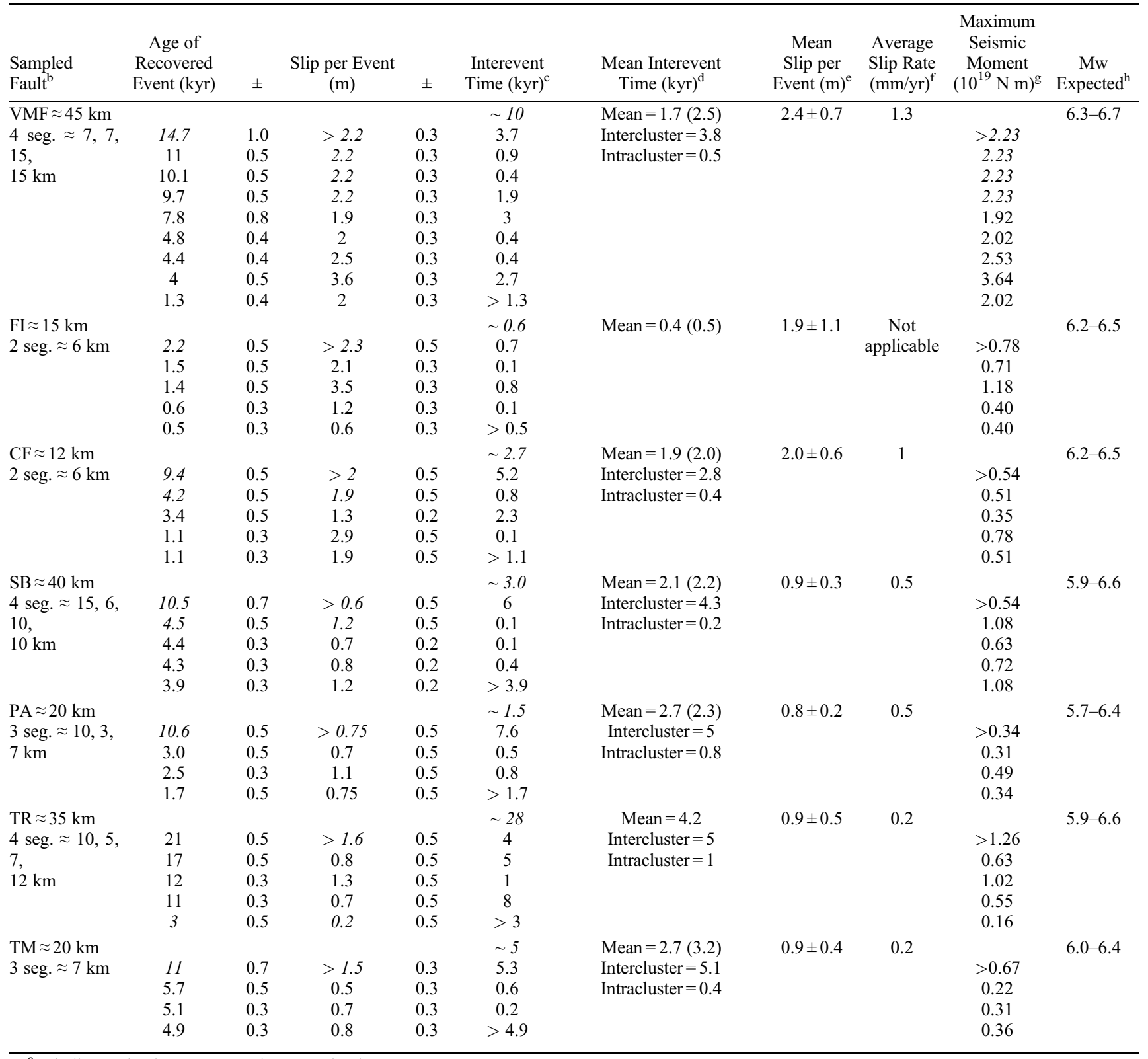

\footnotetext{
${ }^{\mathrm{a}}$ In italic are the data more poorly constrained.

${ }^{\mathrm{b}}$ The fault, along with its total length, its number of major segments, and their lengths.

${ }^{\mathrm{c}}$ The interseismic times deduced between the events; the pre-exposure times are indicated. They represent the interseismic periods prior to the oldest events.

${ }^{\mathrm{d}}$ The average recurrence times, for the entire dataset (first line; in parentheses when pre-exposure time is included), between the clusters (second line), and within the clusters (third line; see text for more details).

${ }^{\mathrm{e}}$ The mean coseismic slip averaged over the multiple event slips. Note that, for VMF, the 4 first values of slip are ignored in the average estimate as they are poorly constrained (see Schlagenhauf et al., 2011).

${ }^{\mathrm{f}}$ The mean fault slip rates deduced for each fault from the entire set of slip-time data.

${ }^{\mathrm{g}}$ Reports the maximum seismic moment determined with the maximum rupture length and a seismogenic width of $15 \mathrm{~km}$ for each event (see table ES4 for details of Mo calculations).

${ }^{\mathrm{h}}$ Reports the magnitude estimates performed in Table ES4.
}

controls the shape of the oldest part of a ${ }^{36} \mathrm{Cl}$ concentration profile, and this allows a fair estimation of its value. Plus, a change in this value mostly influences the ages of the one or two oldest events without affecting the ages of the most recent earthquakes [Schlagenhauf et al., 2010, 2011]. Therefore, in the following models, the oldest events are generally less well constrained than the most recent ones. We discriminate these less constrained events with specific symbols in all the following figures.
[38] Schlagenhauf et al. [2010, 2011] showed that propagating the analytical uncertainty associated with the $\left[{ }^{36} \mathrm{Cl}\right]$ measurements through the model provides a fair determination of the largest uncertainties on the inferred relative ages and slips. Thus, in the following, we only report the errors on event ages and displacements obtained in this way, i.e., using the one standard deviation uncertainty in the measured $\left[{ }^{36} \mathrm{Cl}\right]$ AMS values. Corresponding uncertainties on ages and slips are not 
independent, and are quite modest, generally less than $+/-$ 500 years on the relative ages, and $+/-30-50 \mathrm{~cm}$ on the displacements, for all events but the oldest (for the reasons explained above).

\subsection{Modeling Results}

[39] The data and models we describe below are presented in Figure 3, in Tables 2 and 3 and in Tables S1 to S3 in the supporting information.

\subsubsection{Fucino North System}

\subsubsection{Velino-Magnola Fault}

[40] We modeled $376{ }^{36} \mathrm{Cl}$ data from the Velino-Magnola fault (VMF) and recovered its seismic history in a prior paper [Schlagenhauf et al., 2011]. Therefore, we only summarize here the results that we obtained (Figure E7). We sampled the fault at five sites along its $\sim 45 \mathrm{~km}$ length (Figure 2a, VE, MA1, MA2, MA3, and MA4). We found that the VM fault broke over its entire length in five well-constrained events that occurred at $1.3( \pm 0.4), 4.0( \pm 0.5), 4.4( \pm 0.4)$, $4.8( \pm 0.4)$, and $7.8( \pm 0.8) \mathrm{ka}$ and produced maximum surface slips of $2.0( \pm 0.3), 3.6( \pm 0.3), 2.5( \pm 0.3), 2.0( \pm 0.3)$, and $1.9 \mathrm{~m}( \pm 0.3)$ respectively. Four older events were identified at one site, with ages of $9.7( \pm 0.5), 10.1( \pm 0.5), 11.0$ $( \pm 0.5)$, and $14.7( \pm 1.0) \mathrm{ka}$. Most earthquakes occurred in short, $\sim 1$ ka long clusters, separated by $2-4$ ka long phases of relative quiescence. The five most recent and likely the nine identified events broke the entire fault and produced maximum surface slips of 2-3 m.

\subsubsection{Fiamignano Fault}

[41] We sampled one site (FI) on the Fiamignano fault, $\sim 1$ $\mathrm{km}$ west of the Fiamignano village (Figure 2a, FI and Figure E1). The height of the well-preserved scarp is $\sim 20 \mathrm{~m}$, of which we sampled the first $9.4 \mathrm{~m}$ (samples FI-1 to FI-95). The lowest $1 \mathrm{~m}$ high section of the scarp dips $63^{\circ} \mathrm{SW}$, while the rest of the scarp dips more gently by $\sim 40^{\circ} \mathrm{SW}$.

[42] At surface, the total mean production rate is 44.7 at. of ${ }^{36} \mathrm{Cl}$ per gram of rock per year. ${ }^{36} \mathrm{Cl}$ concentrations at site $\mathrm{FI}$ vary from base to top between 5.0 and $1210^{4}$ atoms of ${ }^{36} \mathrm{Cl}$ per gram of rock (Figure 3). In addition to that at the base of the scarp, four major discontinuities are identified in the ${ }^{36} \mathrm{Cl}$ profile, at $\sim 6,7.8,9$, and $1110^{4}$ at. of ${ }^{36} \mathrm{Cl} . \mathrm{g}^{-1}$ (Figure 3). The discontinuities are clear and suggest a unique scenario with five exhumation events. Modeling of this scenario yields ages for the corresponding exhumation events of $0.5( \pm 0.3), 0.6( \pm 0.3), 1.4( \pm 0.5), 1.5( \pm 0.5)$, and 2.2 $( \pm 0.5) \mathrm{ka}$ and associated slips of $0.6( \pm 0.3), 1.2( \pm 0.3)$, $3.5( \pm 0.3), 2.1( \pm 0.3)$, and $2.3( \pm 0.5) \mathrm{m}$, respectively. The best preexposure duration that we found is $\sim 1 \mathrm{ka}$. Slip of the oldest event is a minimum value since the scarp extends farther up but is too eroded to be analyzed. For the same reasons, the age of the oldest event is less well constrained than that of the other events.

[43] Figure E8 shows alternative scenarios where additional discontinuities have been added at places where subtle groupings in $\left[{ }^{36} \mathrm{Cl}\right]$ are suggested. The increase of the metrics for these more complex scenarios shows that none of them is well supported by the data. In any case, adding more discontinuities does not modify the event ages, which confirms that the ages reported on Figure 3a are robust.

\subsubsection{Campo-Felice Fault}

[44] We sampled one site in the central part of the Campo Felice fault where the total scarp height is $17 \mathrm{~m}$ and dips $55^{\circ} \mathrm{S}$ (Figure 2a, CF, and Figure E2). We sampled only the well-preserved part of the scarp, a height of $8.9 \mathrm{~m}$ (CF-1 to CF-77).

[45] The Campo-Felice site, at $1595 \pm 5 \mathrm{~m}$ a.s.l., has a total mean production rate of 55.3 at. of ${ }^{36} \mathrm{Cl}$ per gram of rock per year. At such an elevation, the snow cover generally lasts $\sim 4$ months, as observed in the last decade (http:// www.caputfrigoris.it/). If the snow cover duration was similar during the Holocene, which is unknown, we infer from the theoretical calculations performed by Schlagenhauf et al. [2010] that, though quite long, this time of snow shielding could not significantly alter the ${ }^{36} \mathrm{Cl}$ production; ages would at most be overestimated by 200 years.

[46] The $\left[{ }^{36} \mathrm{Cl}\right]$ concentrations vary from scarp base to top between 1.3 and $6.210^{5}$ atoms of ${ }^{36} \mathrm{Cl}$ per gram of sample (Figure 3b). The low uncertainties on the ${ }^{36} \mathrm{Cl}$ measurements (1-2\%) cause the PDF distribution to be noisy. Four major discontinuities are, however, identified in the PDF (plus that at the scarp base), at $1.8,3.6,4.3$, and $610^{5}$ at. of ${ }^{36} \mathrm{Cl} . \mathrm{g}^{-1}$ of rock (Figure $3 b$ ). Modeling those discontinuities gives exhumation ages of $1.1( \pm 0.3), 1.1( \pm 0.3), 3.4( \pm 0.5), 4.2$ $( \pm 0.5)$, and $9.4( \pm 0.5) \mathrm{ka}$ and associated slips of $1.9( \pm 0.5)$, $2.9( \pm 0.5), 1.3( \pm 0.2), 1.9( \pm 0.5)$, and $2.0( \pm 0.5) \mathrm{m}$, respectively. The best fitting preexposure duration is $2.7 \mathrm{ka}$. The slip of the oldest event is a minimum value as only $\sim 1 \mathrm{~m}$ above the upper discontinuity could be sampled. The age of the oldest event is thus poorly constrained. The slip of the next event may be overestimated since there is a large sampling gap that may obscure additional events. In contrast, its age is well constrained; splitting the event into two subevents does not change the age (Figures $3 \mathrm{~b}$ and E9). Furthermore, the scenario with two subevents is less likely than the one with a single event, as suggested by the AICc increase. Although it is quite clear that the two narrow peaks at $\sim 2.2$ and 2.4 at. of ${ }^{36} \mathrm{Cl} . \mathrm{g}^{-1}$ of rock are artifacts that result from very small uncertainties on a few measurements, Figure E9 models one of such "discontinuity." On the one hand, the increase of the metrics confirms that this more complex scenario is not well supported by the data. On the other hand, the ages are unchanged, which confirms that event ages reported on Figure $3 \mathrm{~b}$ are robust.

\subsubsection{Southern Fucino System}

\subsubsection{San Sebastiano Fault}

[47] Near the small chapel of San Sebastiano, we sampled the well-preserved part of the scarp over $4.5 \mathrm{~m}$ high (samples SB-01 to SB-45). The upper $5 \mathrm{~m}$ is more eroded (Figure 2a, $\mathrm{SB}$, and Figure $\mathrm{E} 3$ ).

[48] The ${ }^{36} \mathrm{Cl}$ concentrations vary from 2.2 to $5.710^{5}{ }^{36} \mathrm{Cl}$ at. $\mathrm{g}^{-1}$ of rock, with a total mean production rate of 39.2 at. of ${ }^{36} \mathrm{Cl}$ at. $\mathrm{g}^{-1}$ of rock. $\mathrm{yr}^{-1}$. In the first $\sim 1.2 \mathrm{~m}$ of the scarp, data are sparse and with low uncertainties so that the multiple peaks in the PDF are likely meaningless (but that at the base of the scarp). Over the higher portion of the scarp, the PDF curve shows four clear discontinuities (associated with $>4$ data and not due to low uncertainties on one or few data), at $\sim 2.8,3.3,3.8$, and $5.410^{536} \mathrm{Cl}$ at./g of rock. Modeling these discontinuities yields five exhumation events at 3.9 $( \pm 0.3), 4.3( \pm 0.3), 4.4( \pm 0.3), 4.5( \pm 0.5)$, and 10.5 $( \pm 0.7) \mathrm{ka}$, having slips of $1.2( \pm 0.2), 0.8( \pm 0.2), 0.7$ $( \pm 0.2), 1.2( \pm 0.5)$, and $0.6( \pm 0.5) \mathrm{m}$, respectively (Figure 3c). The best fitting preexposure that we find is $3 \mathrm{ka}$. The modeling that we obtain is not entirely satisfying, however, as shown in Figure 3c where the uppermost 
section of the ${ }^{36} \mathrm{Cl}$ profile $(>\sim 2.7 \mathrm{~m})$ appears poorly fitted. We could not find any better model that would more properly adjust the entire dataset. Therefore, we only retain the robust part of the results, that is, the upper $\sim 2 \mathrm{~m}$ of the scarp were exhumed between $\sim 4$ and $11 \mathrm{ka}$ in one or more events, while its lowest $\sim 3 \mathrm{~m}$ were exposed in less than 500 years about $4 \mathrm{ka}$ ago, in three events. An historical slip, such as the one that occurred nearby in 1915, is not supported by the data (Figure E10). Figure E10 shows more complex models where additional discontinuities have been added at the different places where more ambiguous peaks show in the summed PDF function. In all cases, adding more discontinuities and hence more events worsens the fits, while ages are unchanged. The scenario and event ages reported on Figure $3 \mathrm{c}$ are thus robust.

\subsubsection{Parasano Fault}

[49] We sampled the Parasano (PA) site at the center of the eastern fault segment, down the totality of the well-preserved $55^{\circ} \mathrm{SW}$ dipping scarp, over $3.3 \mathrm{~m}$ long (Figure $2 \mathrm{~b}, \mathrm{PA}$, and Figure E4).

[50] ${ }^{36} \mathrm{Cl}$ concentrations are found to vary between 2.0 and $4.310^{5}{ }^{36} \mathrm{Cl}$ at. $\mathrm{g}^{-1}$ of rock (Figure $3 \mathrm{~d}$ ), with a total mean production rate of $32.8{ }^{36} \mathrm{Cl}$ at.g $\mathrm{g}^{-1}$ of rock per year. The PDF analysis results in a smooth curve with no clear prominent peak. This is partly due to the narrow range of concentrations that are found at the site. Three discontinuities are, however, highlighted in the PDF, at about 2.3, 3.1-3.2, and 3.8-3.9 ${ }^{36} \mathrm{Cl}$ at. $\mathrm{g}^{-1}$ of rock (the narrow high peak at $\sim 3.7$ is an artifact). Modeling these three discontinuities yields exhumation events at $1.7( \pm 0.5) \mathrm{ka}, 2.5( \pm 0.3) \mathrm{ka}, 3.0( \pm 0.5) \mathrm{ka}$, and 10.6 $( \pm 0.5) \mathrm{ka}$, having produced slips of $0.75( \pm 0.5) \mathrm{m}, 1.10( \pm$ $0.5) \mathrm{m}, 0.70( \pm 0.5) \mathrm{m}$, and $0.75( \pm 0.5) \mathrm{m}$, respectively (Figure 3d). The most likely preexposition is of 1 ka. Figure E11 shows more complex models where additional discontinuities have been added: in Figure E11a to explore the possibility of a 1915 slip, in Figure E11b to attempt better fitting the upper section of the profile, and in Figure E11c to include the subtle discontinuity suggested by a few points at $\sim 2.7$ at ${ }^{36} \mathrm{Cl}$ at. ${ }^{-1}$ of rock. In all cases, adding more discontinuities and hence more events worsens the fit, while ages are basically unchanged (but in Figure E11a for the youngest imposed event). The scenario and event ages reported on Figure $3 \mathrm{~d}$ are thus the most robustly constrained. The data show that the Parasano fault did not break in 1915.

\subsubsection{Trasacco Fault}

[51] We sampled the TR site in the middle of the central Trasacco segment where the well-preserved scarp is $4.7 \mathrm{~m}$ high and dipping $65^{\circ} \mathrm{SW}$ (Figure 2b, TR, and Figure E5; samples TR-1 to TR-45). At the base of the limestone scarp, the colluvium is indurated and vertically offset, forming a 20 to $90 \mathrm{~cm}$ high scarplet (Figure E5). The lowest meter of the limestone scarp appears as a fresh, lichen-free surface (Figure E5b).

[52] ${ }^{36} \mathrm{Cl}$ concentrations vary between $\sim 410^{5}$ and $1.410^{6}$ at. of ${ }^{36} \mathrm{Cl}$ per gram of rock (Figure 3e), with a total mean production rate of 26.8 at. of ${ }^{36} \mathrm{Cl}$ per gram of rock per year, the lowest production rate among all sites and the highest ${ }^{36} \mathrm{Cl}$ concentrations. The PDF highlights four most prominent peaks and hence discontinuities at about 3.8-3.9, 4.5, 6.5, and $7.610^{5}$ at. of ${ }^{36} \mathrm{Cl} . \mathrm{g}^{-1}$ of rock (Figure $3 \mathrm{e}$ ). Modeling these discontinuities yields five exhumation events at $3( \pm 0.5) \mathrm{ka}$, $11( \pm 0.3) \mathrm{ka}, 12( \pm 0.3) \mathrm{ka}, 17( \pm 0.5) \mathrm{ka}$, and $21( \pm 0.5) \mathrm{ka}$, having produced slips of $0.2( \pm 0.5) \mathrm{m}, 0.7( \pm 0.5) \mathrm{m}, 1.3$ $( \pm 0.5) \mathrm{m}, 0.8( \pm 0.5) \mathrm{m}$, and $1.6( \pm 0.5) \mathrm{m}$, respectively (Figure 3e). The best fitting preexposure that we find is surprisingly long, of $28 \mathrm{ka}$. The youngest, $\sim 3 \mathrm{ka}$ old event is defined from a few points only and hence is not strongly constrained. Attributing that $25 \mathrm{~cm}$ exhumation to a 1915 slip produces a similar fit (Figure E12), and therefore, it is unclear whether the most recent event on TR is the 1915 earthquake or an earlier $\sim 3$ ka old event. Conversely, we note that modeling the data without a $25 \mathrm{~cm}$ slip event degrades the fit, what confirms that a young, $<3 \mathrm{ka}$ event broke the TR fault (Figure E12). Figure E12 models the data with additional discontinuities where more subtle peaks are suggested in the summed PDF. As before, adding more events degrades the fit while ages basically keep unchanged.

\subsubsection{Tre Monti Fault}

[53] We sampled the TM site at the western end of the western segment where the cumulative displacement is nearly maximum ( $400 \mathrm{~m}$, Figure $2 \mathrm{~b}-\mathrm{c}$, TM, and Figure E6). Over the $3.5 \mathrm{~m}$ high, $72^{\circ} \mathrm{SE}$ dipping preserved scarp, we sampled the lowest, most preserved $2.7 \mathrm{~m}$ (samples TM-1 to TM-27).

[54] ${ }^{36} \mathrm{Cl}$ concentrations vary from 2.3 to $4.610^{5}$ atoms of ${ }^{36} \mathrm{Cl}$ per gram of sample (Figure $3 \mathrm{f}$ ), with a total mean production rate of 28.2 at. of ${ }^{36} \mathrm{Cl}$ per gram of rock per year. In addition to that at the scarp base (first pronounced peak in the PDF), three discontinuities are identified in the PDF analysis, at about $2.7-2.8,3.2$, and $3.710^{5}{ }^{36} \mathrm{Cl}$ atom per gram of rock (Figure 3f). Modeling these discontinuities yields four exhumation events at $4.9( \pm 0.3), 5.1( \pm 0.3)$, $5.7( \pm 0.5)$, and $11( \pm 0.7)$, having produced slips of 0.8 $( \pm 0.3), 0.7( \pm 0.3), 0.5( \pm 0.3)$, and $1.5( \pm 0.3) \mathrm{m}$, respectively (Figure 3f). The best fitting preexposition is of $5 \mathrm{ka}$. As before, adding discontinuities in zones of subtle peaks worsens the fit while ages basically keep unchanged (Figure E13). In particular, introducing a 1915 event into the modeling markedly decreases the fit quality and hence is not a likely solution (Figure E13). The most robustly constrained scenario is thus the one presented in Figure $3 \mathrm{f}$.

\section{Additional Information From Independent Paleoseismological Data and Historical Earthquake Catalogues}

\subsection{Paleoseismological Information}

[55] Paleoseismological trenching has been conducted on the Monte Ocre [Salvi et al., 2003], Ovindoli-Pezza [Pantosti et al., 1996], Parasano, Serrone, Trasacco, and Luco dei Marsi faults [Michetti et al., 1996; Galadini and Galli, 1999]. The paleoearthquake records extend from 1915 $\mathrm{AD}$ to $\sim 20 \mathrm{ka}$, and their summary is presented in Table 1.

\subsection{Fucino North System}

[56] Pantosti et al. [1996] analyzed seven trenches at three sites across the Ovindoli-Pezza fault and found evidence in most of those trenches for two large earthquakes, one younger than $1 \mathrm{ka}$, the other one of 3-4 ka. The slips of these two earthquakes could be measured and each is $2.5-3 \mathrm{~m}$. Another $>7 \mathrm{ka}$ large earthquake was suggested in a single trench and hence is poorly constrained.

[57] Salvi et al. [2003] trenched the Monte Ocre fault and found evidence for four large earthquakes, whose ages, 
however, could not be accurately determined. Two of those events might have ruptured the fault in the last $7.6 \mathrm{ka}-$ one possibly in the period $0.6-3.7 \mathrm{ka}$, whereas another earthquake might have occurred in the range 7.6-20 ka.

\subsection{Fucino South System}

[58] The three faults that clearly broke in the 1915 Avezzano earthquake have been extensively studied through trenching (Serrone, Trasacco NW, and Luco dei Marsi) [Michetti et al., 1996; Galadini and Galli, 1999]. The Parasano fault has also been trenched in its northernmost section. The results from 16 trenches across these faults show unambiguously that the Serrone, Trasacco NW, and Luco dei Marsi faults broke together in 1915. In contrast, there is no clear evidence that the Parasano fault broke in 1915. An older, $<1.5-2$ ka earthquake was identified on both the Trasacco NW and the Serrone faults, and its slip estimated in the range $0.3-0.7 \mathrm{~m}$. An additional event is well constrained on the Serrone fault, dated in the range $7.1-10.4 \mathrm{ka}$, whereas its slip is suggested, yet poorly defined, at 2-3 m [Galadini and Galli, 1999]. A few other events were suggested on the southern Fucino faults, but none is robustly constrained (see Table 1 for more details).

[59] In the following, we retain and discuss only the events that are well constrained in the trenches (in bold in Table 1).

\subsection{Historical Earthquake Catalogues}

[60] Well-documented historical records exist only since 1300-1400 A.D. in the Lazio-Abruzzo region, from the time when the Benedictines settled [Pantosti et al., 1996]. Prior to $1300 \mathrm{AD}$, it is likely that large earthquakes that might have occurred in the Fucino area would have been felt seriously in Roma, as was the Avezzano earthquake in 1915 (I VI-VII in Rome). Three large events struck Roma prior to $1300 \mathrm{AD}$ (about $0.7 \mathrm{ka}$ ago), at $508 \mathrm{AD}$ (about $1.5 \mathrm{ka}$ ago, damaged the Coliseum), $618 \mathrm{AD}$ (about $1.4 \mathrm{ka}$ ago, $\mathrm{I} \sim \mathrm{V}$ in Rome), and $801 \mathrm{AD}$ (about $1.2 \mathrm{ka}$ ago, I VII-VIII in Rome) [Guidoboni et al., 2007; Boschi et al., 1997]. Four other events are reported at 1298, 1315, 1349, and 1461 AD, that likely had magnitudes on the order or greater than 6 [Stucchi et al., 2007]. Their location is imprecise.

[61] Between 1600 and 1800, five earthquakes of magnitude $>5.9$ are reported in the Lazio-Abruzzo, from south to north, at 1654, 1706, 1762, 1703, and 1639 AD. From 1900 to present, six events have been recorded with magnitude greater than 5.6, in 1922, 1984, 1915, 1933, 1904, 2009, and 1950 from north to south (Figure 1).

\section{Interpretation and Discussion}

\subsection{Limitations of Data and Modeling to Recover Earthquake Histories}

[62] Before interpreting the results, it is important to remember that the number of events derived from the ${ }^{36} \mathrm{Cl}$ method is always a minimum value since small displacements $(<\sim 25 \mathrm{~cm})$ and short recurrence times $(<\sim$ a few 100 years $)$ cannot be detected with this approach. This implies, first, that small and moderate earthquakes $(\mathrm{Mw}<5.5-6)$ cannot be detected; only large events are identified. This implies also that any so-called "event" might be one single earthquake, or several earthquakes that occurred within a few hundred years at the time derived from the modeling. In the later case, the slips of these events would add to produce the measured slip. It is important to realize that, if it is the case, the smaller earthquakes whose addition might appear as a single event in the ${ }^{36} \mathrm{Cl}$ detection, have necessarily a similar age, well defined by that of the apparent single event; otherwise, the ${ }^{36} \mathrm{Cl}$ method would discriminate them.

[63] Although the number of slip events determined with the ${ }^{36} \mathrm{Cl}$ method is always a minimum, we have shown at each site that adding events to those clearly highlighted by the major discontinuities in the ${ }^{36} \mathrm{Cl}$ profiles always degrades the fit between the modeled and the measured concentrations, while the modeled ages of the events keep unchanged. This shows that both the numbers (and hence slips) and ages of the events that we eventually retained are robust.

[64] As any other paleoseismological method, the ${ }^{36} \mathrm{Cl}$ approach detects only the events that produce slip ( $\geq \sim 25 \mathrm{~cm})$ at the ground surface. Therefore, if some of the past large earthquakes were blind, they will be left undetected. However, blind normal ruptures of $\mathrm{Mw} \geq 6$ are rare worldwide, especially on steep planes as those of the Fucino faults.

[65] Except on the Velino-Magnola fault where we could find five appropriate sites, we only found and sampled one single site on the six other faults. Therefore, the seismic history that we recover for these faults is less well constrained that the one that we described on the VMF.

[66] Elementary production rates are still under study, and it is possible that these rates are refined in the future as work is progressing. Although Schlagenhauf et al. [2010] have suggested that those refinements should not modify by more than $1 \mathrm{ka}$ the ages that are presently obtained, uncertainties remain. However, while absolute ages might slightly change if the elementary production rates are revised, the relative ages that we obtain will not. Therefore, the relative slip history that we infer among the faults is well constrained.

\subsection{Slip-Time Relations for the Identified Earthquakes}

[67] The ages and slips of the identified events are reported in Table 3. The preexposure duration has been included for each fault as it approximately represents the interseismic time before the oldest identified event. The time that separates the most recent event and the present provides the minimum length of the interseismic time that follows the most recent event.

[68] All in all, we found that at least 37 large earthquakes broke the Fucino faults in the last $\sim 21 \mathrm{ka}$, with a minimum of 35 in the last $\sim 15 \mathrm{ka}$. For all faults but FI, the window of observation is longer than $10 \mathrm{ka}$, up to $\sim 21 \mathrm{ka}$ for the TR fault. Only the record on FI is much shorter, covering only a few thousand years.

[69] Because we suspect that the largest, principal faults in the system might behave differently than the smaller, secondary faults, in the following text and figures we discriminate the major and secondary faults.

[70] Figure 4 examines whether the earthquake slips and times data might be related by simple "slip-predictable" or "time-predictable" functions [e.g., Schwartz and Coppersmith, 1994, and references therein]. We have discriminated the northern and southern faults that slip at different rates, $1-2 \mathrm{~mm} / \mathrm{yr}$ and $0.2-0.5 \mathrm{~mm} / \mathrm{yr}$, respectively (Table 3 and discussion below). If the size (i.e., slip) of an earthquake on a fault is governed by the length of the interseismic time before that earthquake, the slip-time data would fall on the dashed line in Figures $4 \mathrm{a}$ and $4 \mathrm{~b}$ that represents the 
Slip predictable?
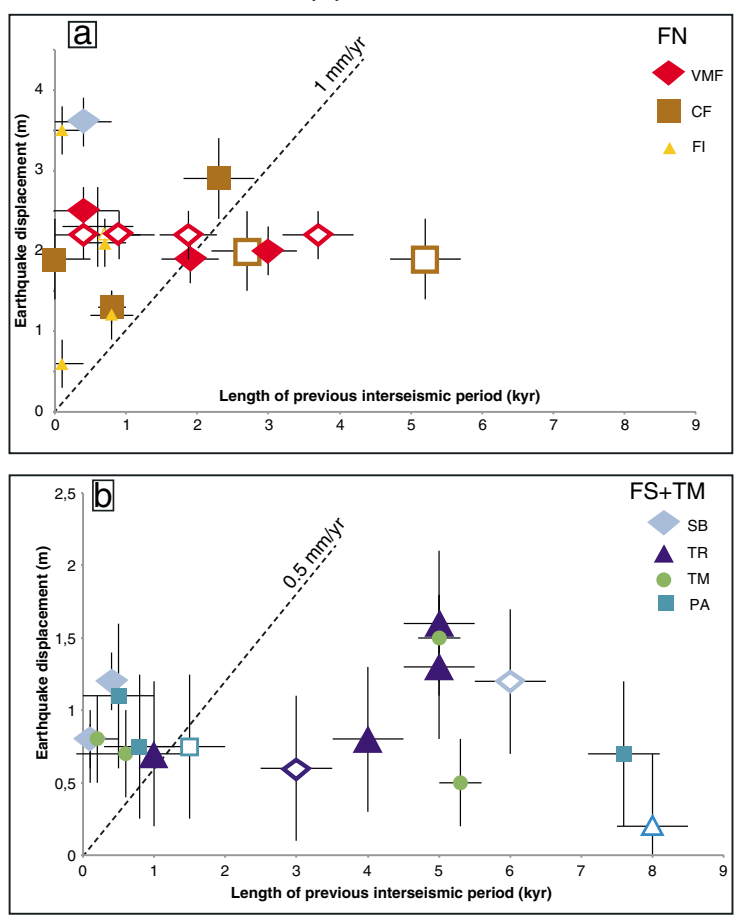

Time predictable?
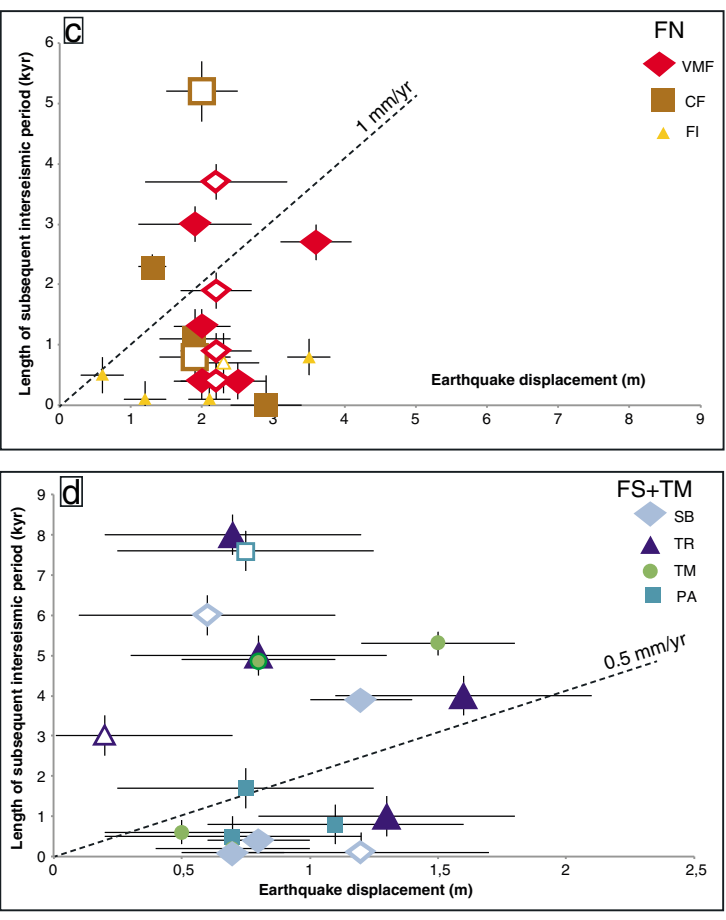

Figure 4. Examining the slip- and time-predictable hypotheses. Symbols are larger for major faults. Full symbols indicate well-constrained data, while empty symbols indicate less well-constrained data. Most events recorded on (a) FN faults or (b) FS faults are not slip predictable nor time predictable (c and d) since most points do not fall on the dashed line that corresponds to the mean slip-rate of the faults $(1 \mathrm{~mm} / \mathrm{yr}$ and $0.5 \mathrm{~mm} / \mathrm{yr}$ for FN and FS faults, respectively). Note that, since the Tre Monti fault has a low slip rate, it is shown with the FS faults.

average slip rate of the fault. Clearly, neither relation characterizes the analyzed faults. Conversely, if the timing of an earthquake on a fault is governed by the amount of slip released by the prior earthquake, the slip-time data would fall on the dashed line in Figures $4 \mathrm{c}$ and $4 \mathrm{~d}$ that represents the average slip rate of the fault. Clearly, this relation is not valid either for any of the analyzed faults. Therefore, our data offer no support to the classical slip- and timepredictable earthquake models.

[71] Figure 5 examines the cumulative earthquake slip versus time on the different faults and systems. The wellconstrained trench data have been included (Table 1).

\subsubsection{FN Fault System}

[72] Nine, five, and five events were recognized from the ${ }^{36} \mathrm{Cl}$ analysis on the $\mathrm{VMF}, \mathrm{CF}$, and FI faults, respectively (Figure 5a). Two events were also identified in trenches on the Ovindoli-Pezza fault (referred to as OP in following). Over the time of $\sim 10 \mathrm{ka}$ when the VMF and the CF faults have a common record, about twice more earthquakes occurred on VMF and produced a cumulative slip almost twice as large ( $\sim 17 \mathrm{~m}$ on $\mathrm{VMF}$ versus $\sim 10 \mathrm{~m}$ on $\mathrm{CF}$ ). These cumulative slips would convert into mean slip rates of $\sim 2 \mathrm{~mm} / \mathrm{yr}$ on the VMF, and half that on the CF. The record on FI and OP is too short to derive a meaningful slip rate. On the four faults, the coseismic slips have a similar range, of 1.0-3.5 m (Tables 1 and 4). On the VMF and CF master faults, the slip record shows a similar pattern, with short, $\sim 1-2$ ka long periods of multiple, clustered earthquakes (grey vertical bands in Figure 5a), interrupted by 1-4 ka long more quiescent phases with no or one event.
The periods of more intense activity are roughly the same for the two faults, around $\sim 1-1.5 \mathrm{ka}, \sim 3-5 \mathrm{ka}$, and $\sim 9-11 \mathrm{ka}$. The secondary OP fault also likely broke during the two most recent phases of clustered earthquakes. The FI fault broke in two large events during the most recent phase of intense activity, but also broke in three events when the two master faults were quiescent.

[73] The 1915 Avezzano earthquake revealed a case where several nearby parallel faults broke in concert during the same event. We might thus wonder whether the events that we found as having a fairly similar age on distinct yet nearby faults could be the same events. As all coseismic slips found per event are larger than $1 \mathrm{~m}$ (but for one event on FI) and more generally on the order of $2 \mathrm{~m}$ (Table 3; see also Table 1 for trench data), it is unlikely that two (or more) similar-age events found on two distinct, $\sim$ parallel faults be the same earthquake since summing a minimum of two events would produce a 3-4 $\mathrm{m}$ slip, a value too high to be realistic (see section 5.4 for a discussion on the slips). In contrast, in the cases where two (or more) similar-age events are found on distinct, yet collinear faults, it is possible that the two (or more) events are the same earthquake, as their slips would not add. The two events recognized in trenches on the OP fault might thus be the similar-age events identified with ${ }^{36} \mathrm{Cl}$ on the collinear $\mathrm{CF}$ fault.

\subsubsection{FS Fault System}

[74] Five, five, and four events were recognized with ${ }^{36} \mathrm{Cl}$ on the SB, TR (central segment), and PA faults, respectively (Figure 5b). Four events are also suggested from trench data 

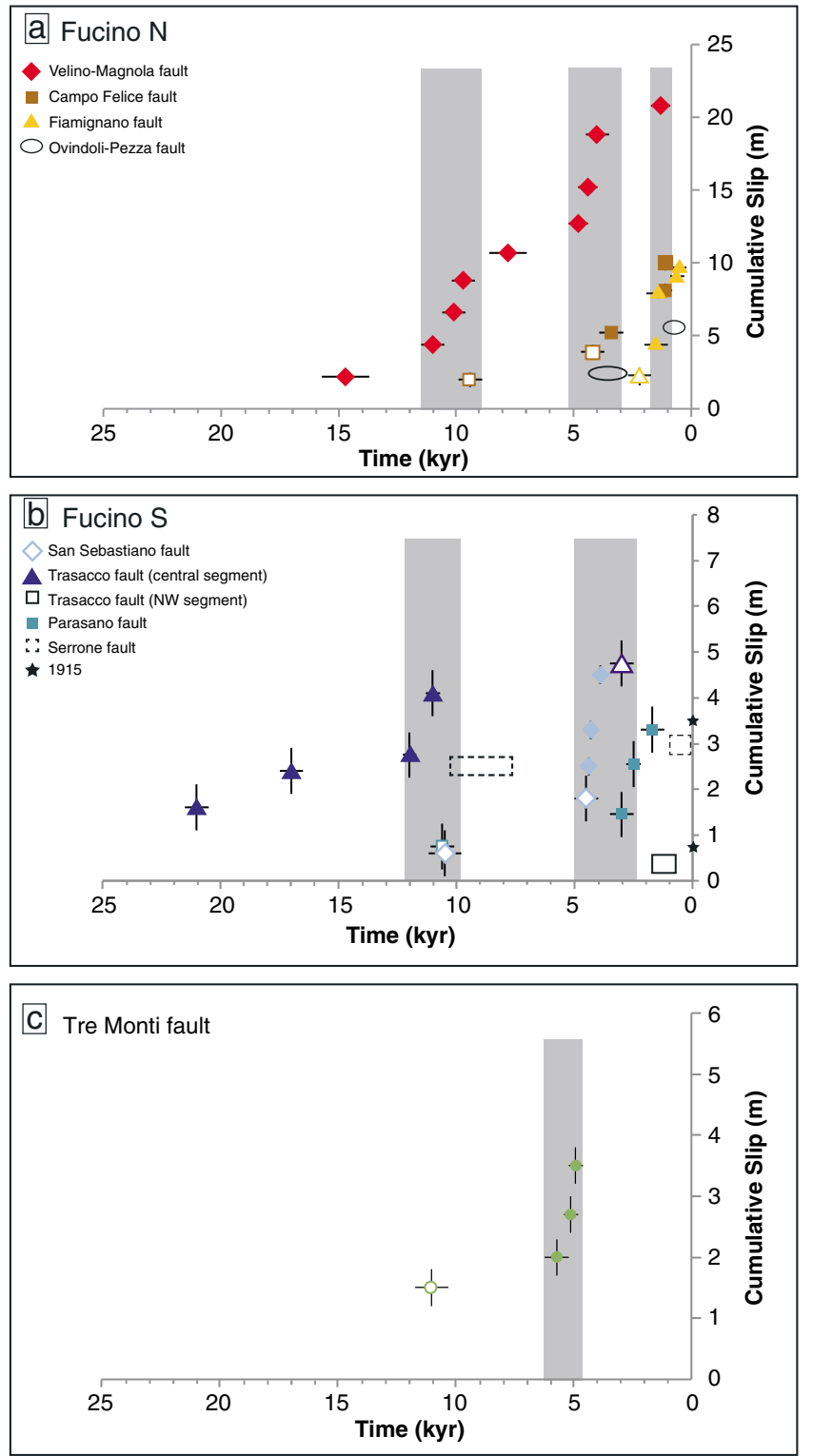
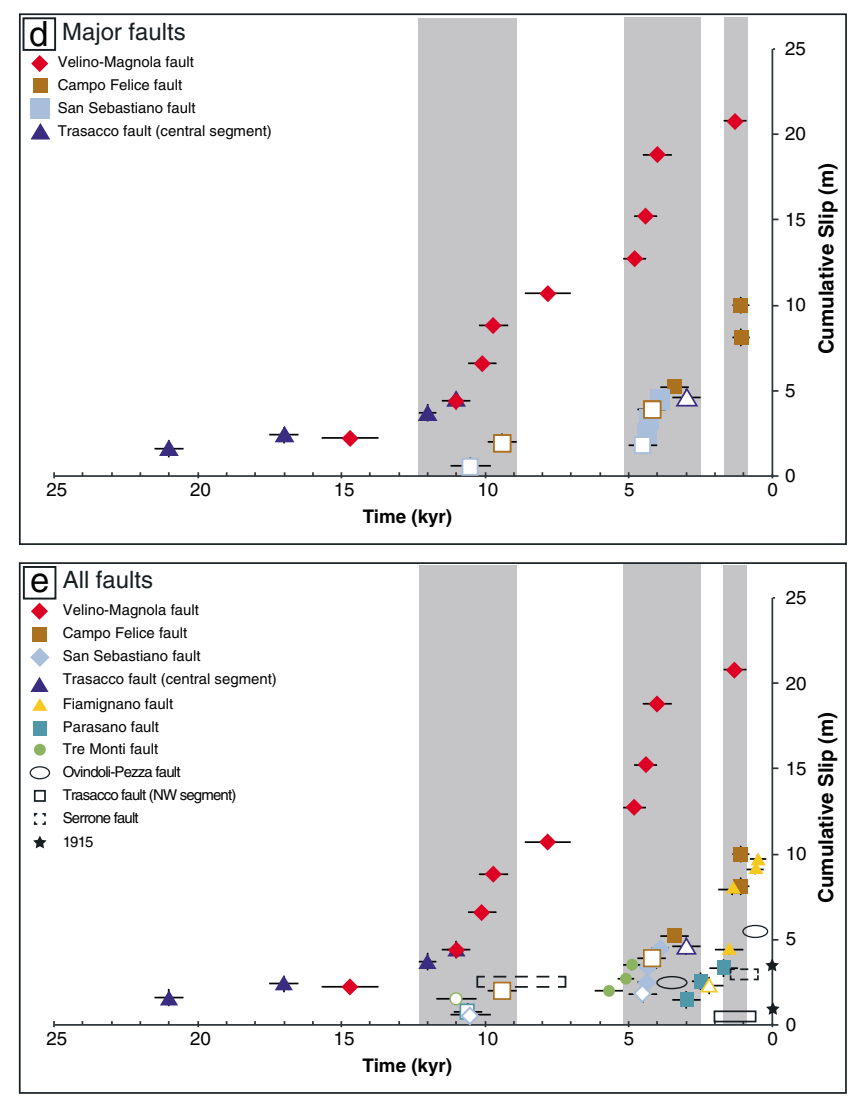

Figure 5. Cumulative slip versus time of the seismic events recovered from the ${ }^{36} \mathrm{Cl}$ analysis (symbols in color). Wellconstrained trench data have been included (black rectangles or ellipses; Table 3 and references therein), and the 1915 event is indicated with a star. Symbols are larger for major faults. Full symbols indicate well-constrained data, while empty symbols indicate less well-constrained data. (a) slip-time data in Fucino north system, (b) slip-time data in Fucino south system, (c) slip-time data on Tre Monti fault, (d) slip-time data on the major faults only, and (e) slip-time data on all faults, major and secondary. VMF data are from Schlagenhauf et al. [2011]. Grey bands indicate the cluster periods defined for the major faults. In Figures $5 \mathrm{~d}$ and 5e, the red diamond included within a blue triangle around $11 \mathrm{ka}$ indicates the overlap of two distinct, yet similar-age events, one on the VMF fault and one on the TR fault.

on the nearby Serrone fault and on the northwestern segment of the TR fault (Figure 5b). The ruptures identified in trenches on the NW segment of the TR fault are different from the events identified from ${ }^{36} \mathrm{Cl}$ on the central TR segment (uncertainty remains, however, for the 1915 event), what confirms that the two segments are well distinct along the fault (see section 2). Over the time of about $12 \mathrm{ka}$ when the SB, TR (central segment), and PA faults have a common record, they broke in a fairly similar number of earthquakes, and each has a fairly similar cumulative slip $(3-5 \mathrm{~m})$. These cumulative slips would convert into mean slip rates of at most $\sim 0.5 \mathrm{~mm} / \mathrm{yr}$ on the three faults, much less than the rates on the northern faults.
On the three faults, the coseismic slips are in a fairly similar range, on the order of $0.5-1.5 \mathrm{~m}$ (Table 3). On the two major faults (SB and TR central segment), the slip record shows a similar pattern, with short, $\sim 2$ ka long periods of multiple, clustered earthquakes (grey bands in Figure 5b), separated by longer, 2-5 ka more quiescent phases with no major earthquake. The periods of more intense activity are roughly the same for the two master faults, at $\sim 3-5 \mathrm{ka}$ and $\sim 10-12 \mathrm{ka}$. The smaller PA and SE faults, as the northwestern segment of the TR fault, show both common and distinct features with the two master faults. Similar to the major faults, the PA fault mainly broke in the $\sim 3-5$ and $\sim 10-12$ ka periods of intense 

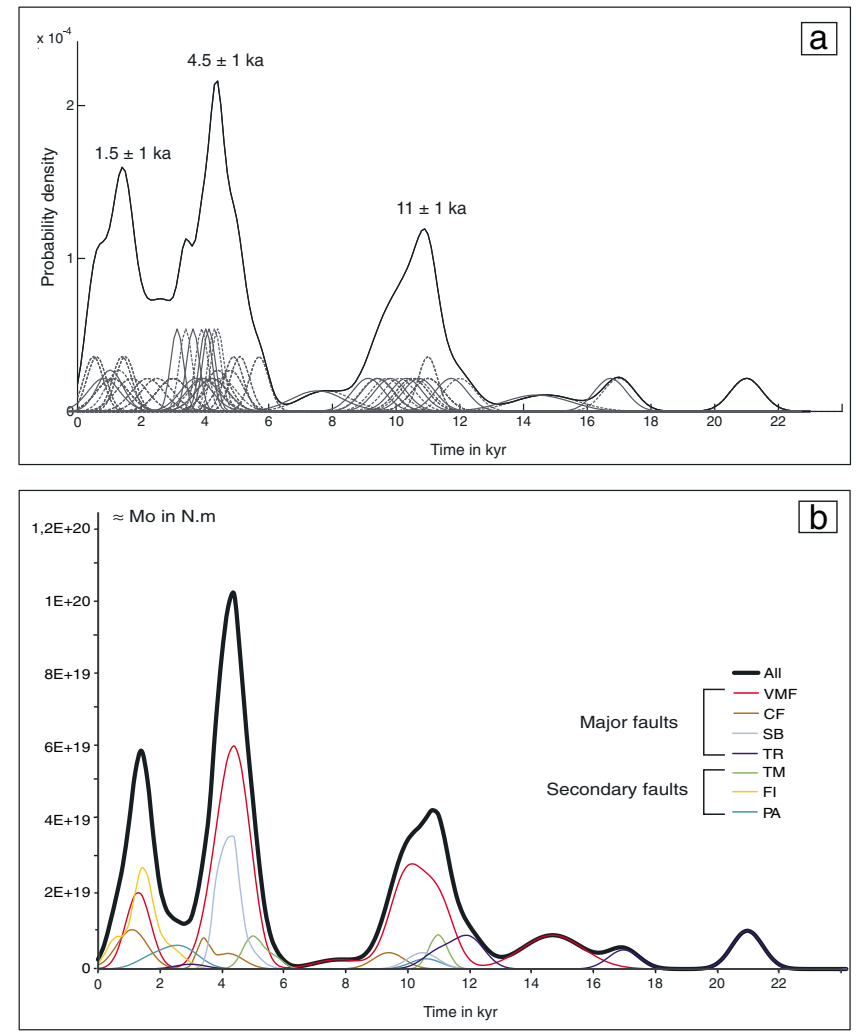

Figure 6. (a) Probability density function of earthquakes ages. In grey are individual earthquake age data on major faults (plain) and on secondary faults (dashed). Those individual ages are assumed to have a Gaussian distribution with a $2 \sigma$ uncertainty, see Table 3. The summed PDF function highlights three prominent peaks at about $11 \pm 1,4.5 \pm 1$, and $1.5 \pm 1 \mathrm{ka}$. (b) Seismic moment release as a function of time. The seismic moment is calculated for each event using its mean slip (taken as half its measured slip, see discussion in Table S4) and the longest rupture length reported in Tables 3 and S4 (values are reported in Table 3). The figure thus presents the maximum values of seismic moment. For each earthquake, the seismic moment is represented by the pdf Gaussian function of the event age, scaled by the seismic moment of the earthquake. Summing the "scaled-pdfs" provides functions that describe the release of seismic moment over time on each fault (different colors) and for all analyzed faults (black curve). Note that, because seismic moments are scaled by the age pdfs, the presented values on the $y$ axis are an approximation of the summed seismic moment, not actual values.

activity. In contrast, it additionally produced one large event in the $\sim 0-2$ ka period when the two master faults were quiet. The SE and TR_NW faults also broke in a few events in the periods when the master faults were quiescent.

[75] As the coseismic slips per event are smaller than in the north, the possibility exists that two slip events identified on distinct $\sim$ parallel faults might have been induced by the same earthquake. Yet, at the times when at least two events occurred fairly simultaneously on such nearby faults (i.e., at about 2.5-3 ka and 10-11 ka), the minimum summed slips would reach $\sim 2 \mathrm{~m}$, that is values that are greater than the average slip per event on the southern faults, and hence are unlikely. As said above, the events identified on the two collinear NW and central segments of the TR fault are different, showing that the two segments behave differently. Therefore, most of the events identified on the southern faults are distinct events.

\subsubsection{Tre Monti Fault}

[76] The Tre Monti earthquake data are shown in Figure 5c. The TM fault broke at two periods of time, one at $\sim 11 \mathrm{ka}$ (one event), and one at 5-6 ka (three clustered events). The slips produced were roughly similar, on the order of $0.5-1.5 \mathrm{~m}$. The total slip accumulated in the last $\sim 10 \mathrm{ka}$ is $\sim 3.5 \mathrm{~m}$, making the Tre Monti fault one of the slowest faults of the Fucino network (Table 3).

\subsubsection{Overall Fucino Network}

[77] Figure 5d highlights the behavior of the four major faults that we analyzed in the Fucino system (VM, CF, SB, and TR). The VMF is the one to break more frequently and with the largest-slip earthquakes. Whether they belong to the FN or the FS systems, all major faults broke in a similar history, principally rupturing at three successive times around $12-9,5-3$, and $1.5-1 \mathrm{ka}$ (grey bands). Those three paroxysmal periods thus lasted $0.5-3 \mathrm{ka}$, and each included at least 3 to 10 large clustered events that broke most, if not all of the major faults. During the most recent phase, only the FN major faults broke. The three phases of clustered activity were separated by 1-4 ka long periods of relative quiescence with no or very few earthquakes on the major faults.

[78] Figure 5e shows all the faults, major and secondary (trench data on secondary faults have thus been included). The periods of intense activity of the major faults are reminded with grey vertical bands. It appears that the secondary faults (FI, OP, PA, SE, TR_NW, TM) also broke primarily during these three specific periods of time, although all also produced a few earthquakes during the more quiescent periods, especially in the last $\sim 1 \mathrm{ka}$ (at least four events) when the major faults were quiet. It is possible that these most recent events "continue" the period of intense activity identified for the major faults at 1.5-1 ka. Surprisingly, despite its singularity in the Fucino network, the oblique Tre Monti fault behaved as the Fucino faults, and also primarily ruptured in all paroxysmal phases but the most recent one. The FI and PA faults - each is a secondary horsetail structure connected to a major fault - behaved in a similar way, rupturing in clustered events some time after their "master" fault had itself broken in clustered events. In detail, the VMF ended its last clustered period at about $4 \mathrm{ka}$, and its secondary FI fault entered a clustered period at about $2.2 \mathrm{ka}$ (as far as we have data). The SB fault produced its last clustered event also at about $4 \mathrm{ka}$, while its secondary PA fault entered a clustered period at about $3 \mathrm{ka}$. This suggests that the Fucino major faults might have broken 1-2 ka earlier than some of their secondary horsetail faults.

[79] Figure 6a provides a synthetic view of the earthquake history in the Fucino system (i.e., the part of the system analyzed here). Each event recognized in the ${ }^{36} \mathrm{Cl}$ data has been represented by its age, with this age shown as a Gaussian whose $2 \sigma$ width is the uncertainty on the age (probability density function representation [Lowell, 1995]). Summing the individual PDFs highlights as pronounced peaks the earthquake ages that are most and/or best represented in the age collection. Three prominent peaks are revealed, confirming that the Fucino fault system dominantly broke at about $11 \pm 1$, $4.5 \pm 1$, and $1.5 \pm 1 \mathrm{ka}$ (uncertainties taken as half-peak width). Although many of the Fucino faults broke during these 

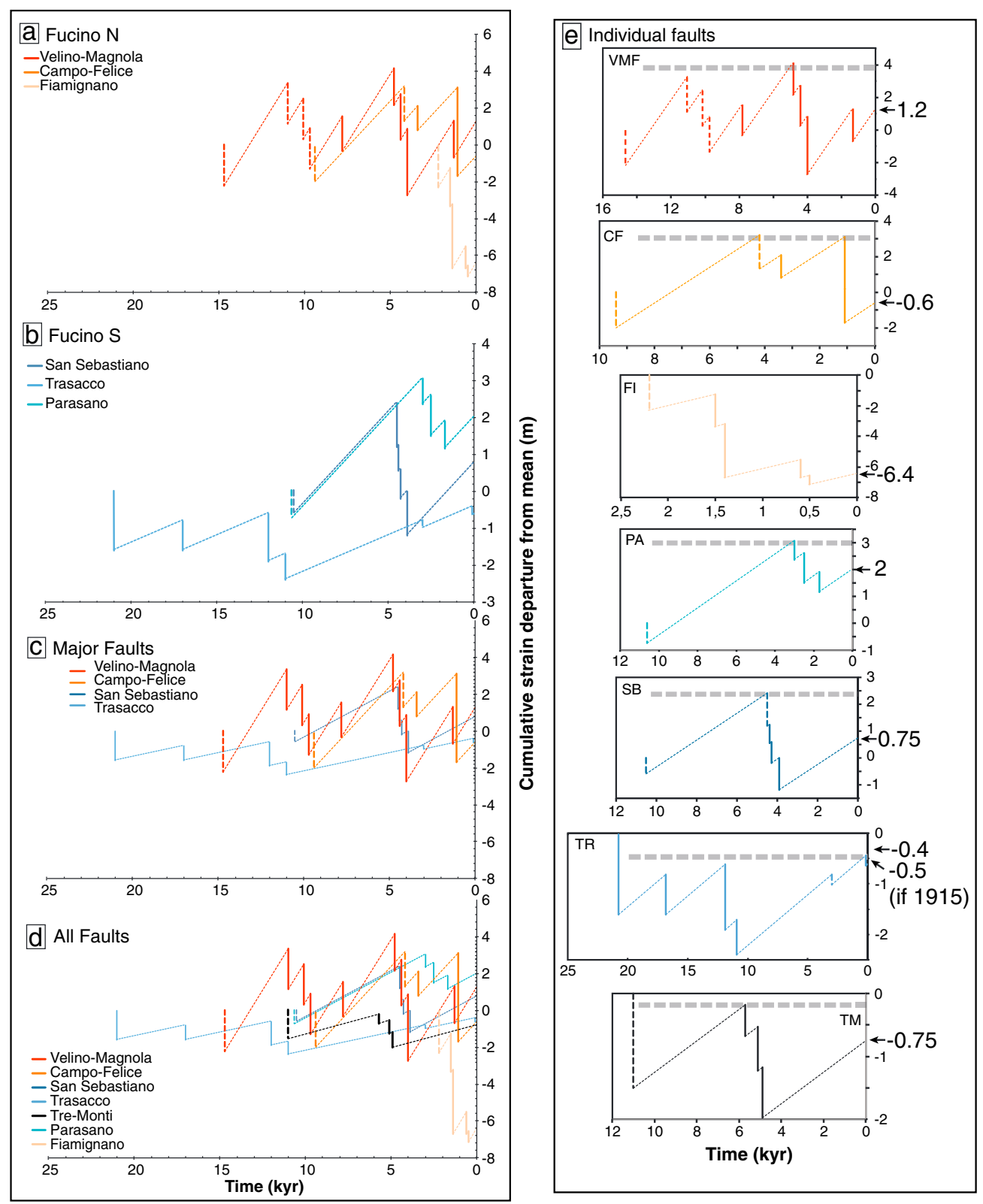

Figure 7. Strain accumulation and release over the last $20 \mathrm{ka}$, (a) on Fucino north faults, (b) on Fucino south faults, (c) on major faults of the Fucino network (northern and southern), (d) on all faults, (e) on each fault. Trench data are not included as their uncertainties are too large. VMF data are from Schlagenhauf et al. (2011). The figures are built assuming a constant slip rate during the loading time (from Table 3). The loading phases are thus indicated with thin dotted lines. Well-constrained events are indicated with solid vertical lines, while less well-constrained events are represented with large dotted vertical lines. In Figure 7e, the horizontal dotted grey lines represent the cumulative relative strain thresholds from which a fault seems to enter a cluster phase (less clear for FI). The present relative strain level on the faults is marked at the right. For TR, the present strain level is also estimated after inclusion of the 1915 earthquake.

specific periods, we must keep in mind that there exist a few other faults in the system that we did not analyze, and hence for which we ignore whether they broke or not at the same times. Note that Figure $6 \mathrm{~b}$ is presented later, in section 5.4 where rupture lengths are discussed.

\subsection{Strain Accumulation and Release}

[80] If we assume that the strain loading on faults is constant through time and equal to the rate of strain accumulation over periods of time long enough to include several seismic cycles, we may estimate the strain accumulation on each analyzed fault and conversely examine how strain has been relieved by the successive paleoevents [Friedrich et al., 2003; Weldon et al., 2004; Schlagenhauf et al., 2011]. Figure 7 shows the strain accumulation and release over time for all the analyzed faults. The strain loading rate on each fault is taken similar to its mean slip rate averaged over the ${ }^{36} \mathrm{Cl}$ observation period (Table 3; except for FI). As the observation time of FI is too short ( $2 \mathrm{ka})$, and since the fault seems 
a
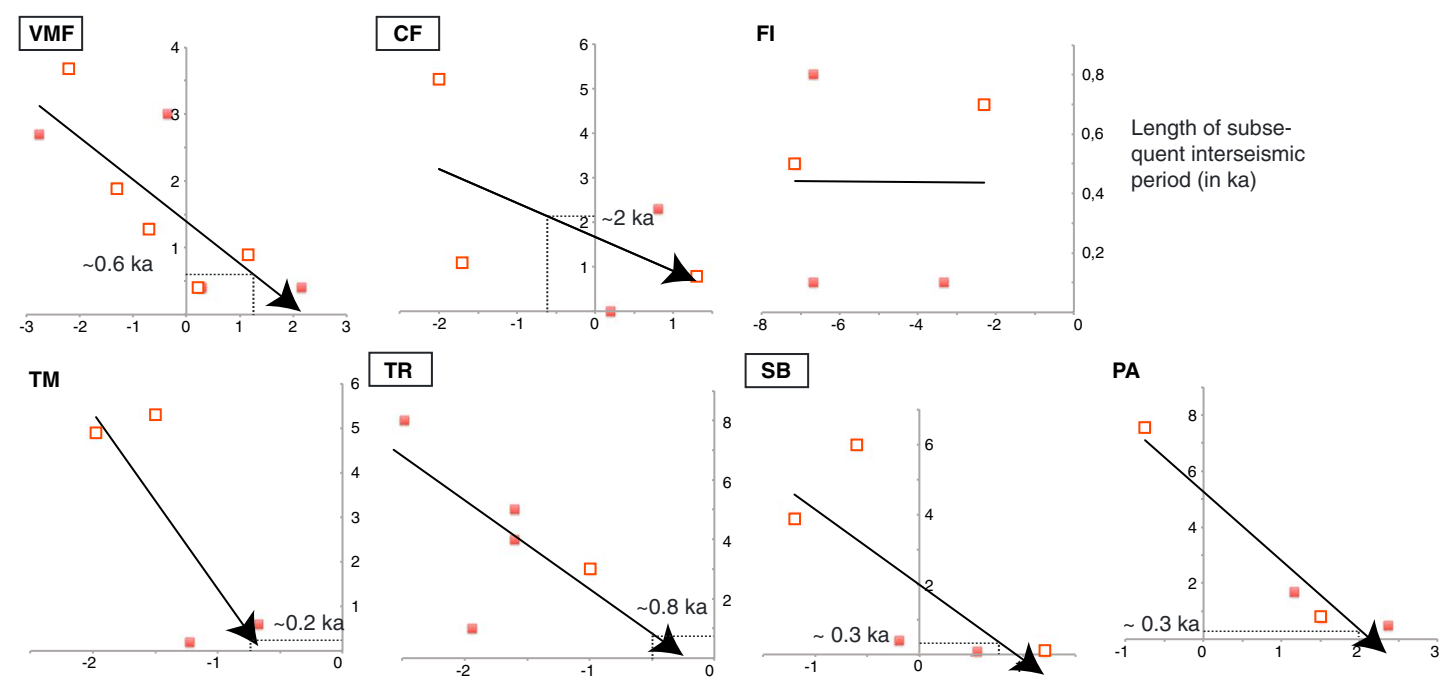

b
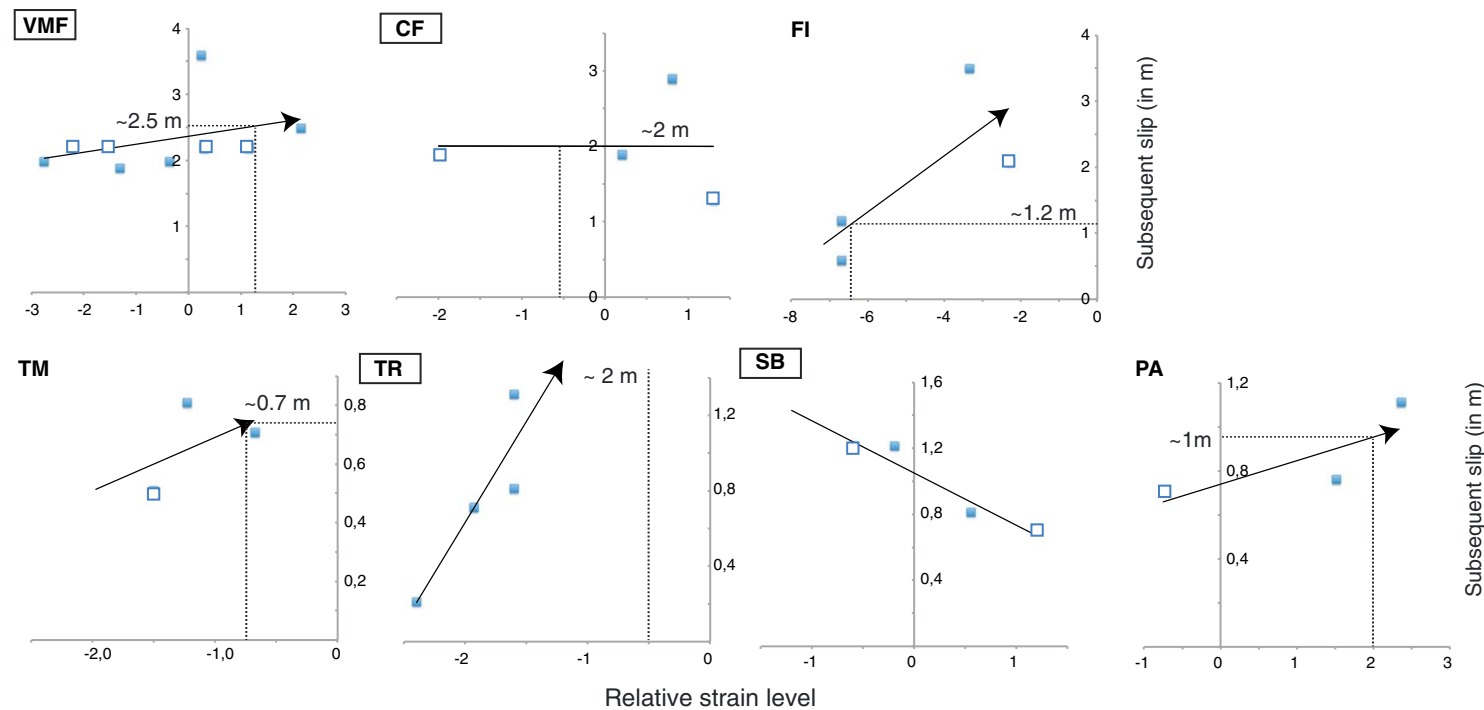

Figure 8. Examining the links between relative strain level on faults, length of subsequent interseismic period, and slip of subsequent earthquake. Full symbols indicate well-constrained data, while empty symbols indicate less well-constrained data. (a) Strain-time relation. On all faults but FI, the data show a fairly linear negative trend, suggesting that relative strain level on a fault controls the time to the next large event. The times estimated from the present (dashed lines) suggest when the next large events might occur on the faults. (b) Strain-slip relation. On all faults but CF and SB, the data show a fairly linear positive trend, suggesting that relative strain level on a fault controls the slip of the next event. The slips expected for the forthcoming events are estimated (dashed lines).

to roughly behave as the VMF (events as frequent and as large), we consider below that the strain loading on FI occurs at a rate similar to that estimated on VMF.

[81] Figures $7 \mathrm{a}$ and $7 \mathrm{~b}$ show the strain accumulation and release accommodated by the Fucino north and the Fucino south faults, respectively. Both figures reveal specific periods of time when several faults showed the same coeval behavior, and, following Scholz [2010], we use the term "synchronization" to describe these coeval and similar behaviors. Figure $7 \mathrm{a}$ highlights the synchronization of the VM and the CF major faults. Both faults show two similar long phases of strain accumulation in the time range $\sim 10-5 \mathrm{ka}$ and $\sim 4-1.5 \mathrm{ka}$, separated by rapid phases of strain release at $\sim 11-10,5-4$, and $1.5 \mathrm{ka}$. While the strain-accumulation phases were free (or almost free) of earthquakes, at least three clustered earthquakes occurred during the strain release phases. The secondary FI fault seems to be synchronized with the two master faults, although the record is too short to properly describe its behavior. Figure $7 \mathrm{~b}$ shows that the two major SB and TR faults in the Fucino south system were also fairly well synchronized since both accumulated strain in the time ranges $\sim 11-5$ and $3-0 \mathrm{ka}$, and relieved strain rapidly at $\sim 11$ 
and 5-3 ka. Though the smaller PA fault had parts of its history synchronized with the two master faults (from $\sim 11$ to 4 $\mathrm{ka})$, its recent behavior partly differed.

[82] Figure 7c shows the major northern and southern faults together. The synchronization of the VM, CF, SB, and TR faults is remarkable, as all four faults released most of the strain they had accumulated at the almost same times, at $\sim 10$ and $\sim 4 \mathrm{ka}$. On all faults, the strain was released similarly, in three to four clustered large earthquakes. The VM and CF northern faults were synchronized at an additional time, around $1.5 \mathrm{ka}$. In between their synchronized periods of strain release, the four major faults have accumulated strain over quiet periods two to three times longer than the periods of strain release.

[83] Figure 7d shows all faults together. Although the smallest faults add more variability to the graphs, the general picture is preserved: all faults were fairly synchronized in both their strain accumulation and their strain release times. That is, the different strain amounts that had accumulated on most of the Fucino faults were essentially relieved at the same three times, at about 10,4, and $1.5 \mathrm{ka}$. This does not preclude that a few other faults, not analyzed here, behaved differently.

[84] Figure 7e shows each fault separately. The amounts of strain to have been relieved highlight which faults were "major" tectonic features over the last $\sim 15 \mathrm{ka}$. It appears that the VM, CF, and SB faults were major structures-as inferred from their tectonic long-term signature - each relieved up to 4-5 $\mathrm{m}$ of strain during the phases of paroxysmal, clustered activity. More surprisingly, the TR fault did not behave as a major structure, only relieving small strain of at most $1.5 \mathrm{~m}$ during the paroxysmal phases. On the contrary, the FI fault behaved as a major structure, and relieved up to $7 \mathrm{~m}$ of strain over the short, 2 ka period of observation. The PA and TM faults behaved as secondary features-as expected, with maximum total strain release of $1.5-2 \mathrm{~m}$.

[85] The alternation between long phases of strain loading and shorter phases of strain release seems to have followed cycles (or "supercycles" as defined by Sieh et al. [2008]). Only the VMF allows the observation of two successive supercycles, but the collective behavior of the faults (Figures 7c and 7d) suggests that most faults actually obeyed this cyclic behavior. On VMF, the supercycles look roughly regular (Figure 7e) (see Schlagenhauf et al. [2011] for more details). Furthermore, Figure 7e suggests that the faults entered into a phase of strain release and hence intense seismic activity once they had reached a specific cumulative relative strain threshold (horizontal dotted lines in Figure 7e). Similar observations have been done on the San Andreas fault [Weldon et al., 2004]. In that hypothesis, the VM, CF, FI, and SB faults are presently still quite far from the strain threshold that may "trigger" a forthcoming event or cluster of events on these faults. By contrast, the PA, TM, and TR faults are approaching or beyond their suspected strain threshold. While the TR fault (central segment here) possibly broke in 1915, the PA fault did not rupture during this historical earthquake, whereas it is not clear whether or not the TM fault ruptured in this earthquake. Oddone [1915] reported open cracks along the TM that might suggest that it ruptured in 1915 , but observations in trenches are not conclusive on this point [Galadini and Galli, 1999] and the ${ }^{36} \mathrm{Cl}$ data do not find this historical event. If the TM fault did not rupture in 1915, seismic hazard related to this fault might be more elevated than presently thought.

[86] Figure 8 provides further insight on the suspected importance of the relative strain level. It examines whether a relationship might exist between the relative strain level on a fault and, on the one hand, the recurrence time of the earthquakes (Figure 8a), and on the other hand, the slip produced by the subsequent earthquake (Figure $8 \mathrm{~b}$ ). Though the data for each fault are few, they are generally compatible with such relations that would make a forthcoming interseismic length and earthquake slip partly controlled by the relative strain level on the fault at the time of the previous large earthquake. The relationships are best defined for the VM, TR, PA, and TM faults. They are less clear yet still plausible for the $\mathrm{CF}$ fault. By contrast, while the strain-slip relation is plausible for the FI fault, there is no clear relationship between strain level and interseismic time for that fault. Conversely, while the strain-time relation is verified for the SB fault, the relationship observed between strain level and slip for that fault is opposite to common expectation.

[87] The findings above suggest that the relative strain level might control the size, the time of occurrence, or both, of the large earthquakes on a fault. The regressions that we calculated among the data on Figures $8 \mathrm{a}$ and $8 \mathrm{~b}$ allows approaching the time spans that might be expected from now on before the next large events occur on the faults, as the slips these forthcoming events might produce. The CF seems to be farther from failure, with an elapsed time estimated to $\sim 2 \mathrm{ka}$ from the present. The two major TR and VMF faults might each rupture in a large earthquake over the next $\sim 0.8$ and $\sim 0.6 \mathrm{ka}$, respectively, both producing a slip at the ground surface of $2-2.5 \mathrm{~m}$. Although the regression is poorly constrained for $\mathrm{SB}$, it suggests that the SB fault might break over the next $\sim 0.3 \mathrm{ka}$. If the PA fault did not rupture in the 1915 event, what is likely, the elapsed time before the next event is estimated to $\sim 0.3 \mathrm{ka}$. While the time of the forthcoming rupture on the FI fault cannot be estimated, the slip produced by this next large event might reach $\sim 1 \mathrm{~m}$. If the TM fault did not break in 1915, we anticipate from Figure 8a that it might rupture very soon $(\sim 0.2 \mathrm{ka})$, possibly over the next century, with a slip on the order of $0.7 \mathrm{~m}$ (Figure $8 \mathrm{~b}$ ).

\subsection{Recurrence Times, Coseismic Slips, Rupture Lengths, Magnitudes, and Seismic Moments of the Large Earthquakes on the Fucino Faults}

[88] The interevent times reported in Table 3 allow calculating the average recurrence time of the large earthquakes on each fault. Average recurrence times of 2-3 ka seem to be the norm on the Fucino faults, with the marked exception of Fiamignano $(0.5 \mathrm{ka})$. In more details, the average recurrence time of the large earthquakes during the paroxysmal periods is $0.5,0.4,0.2$, and $1.0 \mathrm{ka}$ on the major $\mathrm{VM}, \mathrm{CF}$, $\mathrm{SB}$, and TR faults, while it is 0.8 and $0.4 \mathrm{ka}$ on the PA and TM secondary faults (preexposure times included). The recurrence times of the large events during the paroxysmal phases are thus on the same order on all faults, $0.5 \pm 0.3 \mathrm{ka}$. The short $0.5 \mathrm{ka}$ average recurrence time of the slip events on the FI fault is similar to the average recurrence time of the large earthquakes during the clustered phases, which suggests that the FI fault might be presently in a phase of paroxysmal activity. The times that separate the paroxysmal phases 
average $3.8,2.8,4.3,5.0,5.0$, and $5.1 \mathrm{ka}$ on the VM, CF, SB, TR, PA, and TM faults (preexposure times included), and hence are all on the order of $4.3 \pm 0.9 \mathrm{ka}$. We must keep in mind that the above recurrence times are maximum values as smaller and/or roughly synchronous earthquakes might have occurred and not being detectable in the ${ }^{36} \mathrm{Cl}$ data.

[89] Table 3 also provides the coseismic slips that we measured for the various events. These slips were measured at sites along the faults where the recently exhumed scarp was the highest and the best preserved. These sites were generally found coinciding with the zones of maximum cumulative slip on the fault (Figure 2c). We thus consider that the slips that we measured provide a fair estimate of the maximum coseismic slips produced at the ground surface by the large paleo-earthquakes.

[90] On all faults, the slips vary from one event to the next, with differences between lowest and largest values in the range $1-1.5 \mathrm{~m}$ for all faults but FI. The average slip per event is $2.3 \pm 0.5,2.0 \pm 0.6$, and $1.9 \pm 1.1 \mathrm{~m}$ on the northern $\mathrm{VM}$, $\mathrm{CF}$, and FI faults, while it is $0.9 \pm 0.3,0.9 \pm 0.5,0.8 \pm 0.2$, and $0.9 \pm 0.4 \mathrm{~m}$ on the southern SB, TR, PA, and TM faults. Thus, large paleo-earthquakes have produced at most $\sim 2 \mathrm{~m}$ of slip on the northern Fucino faults, and twice less on the southern faults (including TM). The $\leq 1 \mathrm{~m}$ average slip found for the southern events is in keeping with the amount of slip produced on individual faults by the 1915 Avezzano earthquake [Oddone, 1915].

[91] The active normal faults that dissect the LazioAbruzzo region, among which are the Fucino faults, are young structures that are generally thought to have initiated less than 1 Ma ago [e.g., Westaway, 1993; Galadini and Galli, 2000; Ghisetti and Vezzani, 2002]. They are thus immature faults as defined in Manighetti et al. [2007]. As such, they are expected to produce earthquakes with fairly high apparent stress drops, and hence fairly high slip to length ratios [Manighetti et al., 2007]. Examined in the framework of the updated earthquake scaling relations proposed by Manighetti et al. [2007], the Fucino faults should produce earthquakes having surface slip to length ratios falling on one or other of the two "highest" functions in Figure E14. On the northern Fucino faults, we found that the large earthquakes produced $\leq 2 \mathrm{~m}$ of surface slip on average. We infer that those earthquakes broke at most 10-20 km long fault sections. These lengths are shorter than the length of the entire FNW and FNE fault systems (Table 3), and thus we deduce that the large paleo-earthquakes that we identified in the north did not break these systems entirely. By contrast, the inferred rupture lengths coincide with those of secondary faults (FI) or of major segments within faults (VMF and CF). The large earthquakes identified on the VMF might thus have broken one or two major segments along this $\sim 45 \mathrm{~km}$ long fault, while those identified on the CF and FI faults might have broken either the entire fault or one of its two major, 5-7 km long segments.

[92] On the southern Fucino faults, the large earthquakes produced $\leq 1 \mathrm{~m}$ of surface slip on average. Examining Figure E14, we infer that those earthquakes broke at most $10-12 \mathrm{~km}$ long fault sections. These lengths are shorter than the length of the entire faults (Table 3), and thus we deduce that the large paleo-earthquakes did not break any of the faults entirely. By contrast, the inferred rupture lengths coincide with those of most major segments within the faults. The large earthquakes identified on the SB, TR, and TM faults might thus have broken one of the major segments along each of these faults, while those identified on the PA fault might have broken one or two major, $\sim 7 \mathrm{~km}$ long segments of the fault. These results likely explain why most paleoearthquakes identified in nearby trenches are different from those that we documented with ${ }^{36} \mathrm{Cl}$ data; they are different because they indeed broke different faults or segments.

[93] Schlagenhauf et al. [2011] recovered the Holocene earthquake history of the VMF from the ${ }^{36} \mathrm{Cl}$ analysis at five sites well distributed along the fault. This more complete spatial analysis revealed the same earthquake record at the five sites over $30 \mathrm{~km}$. A paradox then arose, as, on the one hand, each large event was recognized as unable to break more than 10-20 km of length, yet, on the other hand, if single earthquake, the rupture would be $>30 \mathrm{~km}$ long and likely up to $\sim 45 \mathrm{~km}$. To explain this paradox, Schlagenhauf et al. [2011] suggested that the ${ }^{36} \mathrm{Cl}$ events found to be similar along the fault were actually different yet fairly synchronous earthquakes that had occurred in cascade along the fault and made it break entirely in a short time. Results from the VMF might similarly apply to other faults of the Fucino network; each of the large earthquakes during the paroxysmal periods might be an earthquake sequence breaking the entire fault, not a single rupture.

[94] On the basis of our average slip and rupture length estimates, we may evaluate the seismic moments and the magnitudes of the large paleo-earthquakes on the analyzed Fucino faults. We follow the approach described in Schlagenhauf et al. [2011] (details in Table S4 and caption) and report the moment and magnitude calculations in Tables S4 and 3 . Figure $6 \mathrm{~b}$ shows the seismic moment that was released on each fault by the identified ${ }^{36} \mathrm{Cl}$ events as a function of time, along with the total, summed seismic moment released by the seven faults. For each earthquake, the seismic moment is represented by the pdf Gaussian function of the event age, scaled by the seismic moment of the earthquake. Summing the "scaled-pdfs" provides functions that describe the release of seismic moment over time on each fault and in the analyzed part of the Fucino system. Compared with Figure 6a, the graphs confirm, on the one hand, that most faults were synchronized in their phases of strain release, and, on the other hand, that the three specific periods that we identified earlier as multiple-earthquake phases were phases of largest total strain release in the overall system, whereas the long intervals between those paroxysmal phases were low strain release periods. We cannot exclude, however, that other faults, not analyzed here, might have ruptured in the Fucino area during the quiet intervals, such that the overall Fucino network might sustain a more regular strain release than the one documented here on the seven faults.

[95] The large paleo-earthquakes on the northern Fucino faults have estimated magnitudes $\mathrm{Mw}$ in the range 6.2-6.7, while the large events on the southern Fucino faults got slightly smaller magnitudes $\mathrm{Mw}$ in the range 5.7-6.6. If we take the largest slips measured on the faults as produced by single events, we infer that the largest events on the faults had magnitudes $\mathrm{Mw}$ up to $6.7,6.5,6.5,6.6,6.4,6.6$, and 6.4 on the VM, FI, CF, SB, PA, TR, and TM faults, respectively. We must keep in mind that these values might be slightly underestimated as they are based on slip amounts 
measured at the ground surface and hence likely lower than the actual slips produced at seismogenic depth (see discussion in Manighetti et al. [2007]). The magnitude estimates that we obtain are in fair agreement with those of the few recent (L'Aquila 2009, Mw 6.3) and historical (Avezzano, $\mathrm{Mw} \sim 7$ ) earthquakes that have broken the fault zone.

\subsection{Relations With Historical Events}

[96] The 1349 AD Aquilano event (9 September 1349 at 18:00 Imax $\sim$ X) produced maximum damages in the Salto Valley [e.g., Boschi et al., 1997, Stucchi et al., 2007], close to the FI fault. On that fault, we identified two events at 0.5 $( \pm 0.3)$ and $0.6( \pm 0.3) \mathrm{ka}$, one of which could have been the Aquilano earthquake. Ignoring the uncertainties on the ages, the event found at $0.6 \mathrm{ka}$ would be closer in time to the earthquake, and hence, possibly, the most likely source of the historical event. If correct, the magnitude of this event might have been in the range 6.2-6.5, large enough to produce the reported, significant damages. Relating the second ${ }^{36} \mathrm{Cl}$ event $(0.5 \pm 0.3 \mathrm{ka})$ to an historical earthquake is more difficult as we ignore the precise location of the reported historical events (Figure 1a). The 1298, 1461, 1703, and 1762 earthquakes may be poorly located, so one of them might have been the ${ }^{36} \mathrm{Cl}$ event that we recognized between 1200 and 1800 years on the FI fault.

[97] We found that the VMF, CF, FI, and OP faults produced at least seven to eight earthquakes between $\sim 0.5$ and $1.5 \mathrm{ka}$, in a time span where three large historical earthquakes occurred (at 508, 618, and 801 AD) and damaged Roma [Guidoboni et al., 2007]. These historical events must thus have been of large magnitudes. Michetti et al. [1996] speculate that the $<1.4 \mathrm{ka}$ event seen in trenches on the Serrone fault might be the 801 AD earthquake. More recently, Galadini and Galli [1999] and Galadini et al. [2010] have gathered additional evidence and revisited this hypothesis, now attributing the $<1.4 \mathrm{ka}$ trench event to the $508 \mathrm{AD}$ historical earthquake that destroyed the ancient city of Alba Fucens, north of the Fucino area, close to the VM fault. Finally, Pantosti et al. [1996] attributed the ultimate event $(<1 \mathrm{ka})$ recognized in the Piano di Pezza trenches to the 801 AD historical earthquake. Together these suggest that at least one and possibly all three historical events were produced during the cluster of large earthquakes that affected the FN faults in the time range $0.5-1.5 \mathrm{ka}$. As suggested in Table 3, these earthquakes might have got magnitudes Mw up to 6.7.

\subsection{Perspectives on How Large Earthquakes Repeat on Faults}

\subsubsection{Clustered Versus Periodic Earthquakes}

[98] Our data show that the Fucino faults that we analyzed broke in clustered large earthquakes over the last $\sim 15 \mathrm{ka}$, not in quasi-periodic nor random events. Two time scales of clusters are suggested, a possible centennial one (cascade of events along a fault in less than 100-200 years; not discriminated in ${ }^{36} \mathrm{Cl}$ data), and a millennial one (several large earthquakes in 1-2 ka). Although the periods of increased activity might be Poisson clusters in a random distribution [e.g., Sammis and Smith, 2013], the fact that these specific periods are found on seven distinct faults supports that they emerge from a nonrandom, deterministic process. Large earthquakes in central Italy thus repeat with some irregularity, as observed on many faults worldwide [Wallace, 1987; Grant and Sieh, 1994; Goes, 1996; Pirazzoli et al., 1996; Marco et al., 1996; McCalpin and Nishenko, 1996; Stein et al., 1997 Rockwell et al., 2000; Stiros, 2001; Holbrook et al., 2006; Ferry et al., 2007, 2011; Dolan et al., 2007; Sieh et al., 2008; Meltzner et al., 2010; Schlagenhauf et al., 2011]. Why this irregular, yet nonrandom earthquake behavior characterizes some faults whereas other faults produce quasi-periodic and characteristic earthquakes is still an open issue that may partly depend on fundamental differences in fault and crust-lithosphere properties [e.g., Sieh, 1996; Ben-Zion et al., 1999; Chéry et al., 2001a, 2001b; Lynch et al., 2003]. Although the large paleoevents that we identified in the ${ }^{36} \mathrm{Cl}$ data did not follow at regular intervals, they show a bimodal distribution of repeat times $-0.5 \pm 0.3 \mathrm{ka}$ during clusters and $4.3 \pm 0.9$ $\mathrm{ka}$ in between clusters, which suggests a certain form of periodicity. While individual events did not repeat at periodic times, they seemed to occur in several ka long supercycles that might have repeated periodically. Similarly, although the successive paleo-events on a fault did not produce the exact same slips, most of the displacements differed by less than 30\% (Table 3). Therefore, although earthquake slips were not characteristic, they were not dramatically different either.

\subsubsection{The Relative Strain Level on a Fault,}

\section{a Key Factor in Earthquake Occurrence?}

[99] Our data suggest that the level of relative strain accommodated on a fault is a key factor that controls the earthquake occurrence and slip. We first need to remind that the relative strain level is determined upon several assumptions: the strain loading is assumed to be constant over time, and to occur at the average, long-term fault slip rate estimated from the ${ }^{36} \mathrm{Cl}$ data. Although they are generally considered as reasonable [e.g., Weldon et al., 2004], these two hypotheses might not be correct. If we admit that they are correct, the relative strain level on a fault appears to control three key parameters of the large earthquakes: (1) the initiation time of a millennial-scale cluster of large events, (2) the occurrence time of each successive large earthquake, (3) the slip of the forthcoming large event. Although Weldon et al. [2004] already suggested that earthquake occurrence might be strain predictable, this is the first time that such a control of the relative strain level is well documented on many faults and shown to have multiple impacts on earthquake characteristics.

\subsubsection{Synchrony of Large Earthquakes Within Fault Systems}

[100] Our data also show that the seven faults analyzed broke in fuzzy synchrony (i.e., "strong synchronization signal with a large noise component," as defined by Scholz [2010]) over the last $15 \mathrm{ka}$. The synchronization of more than 30 large earthquakes within the Fucino network shows that these earthquakes were causally linked to each other, and hence that the seven faults are coupled and interacting. Earthquake synchronization has been described in other cases worldwide (see synthesis in Scholz [2010]), along individual faults (fairly synchronous earthquakes on different sections of a fault, and hence clustered earthquakes [e.g., Marco et al., 1996; Barka, 1996; Stein et al., 1997; Ferry et al., 2011; Schlagenhauf et al., 2011]), among a few nearby faults [e.g., Rockwell et al., 2000; Bell et al., 2004; 
Vanneste et al., 2006; Dolan et al., 2007], and even possibly at the global scale [e.g., Bufe and Perkins, 2005]. The reasons evoked to account for such a synchronization are stress transfers [e.g., Goes, 1996; Chéry et al., 2001a, 2001b; Friedrich et al., 2003; Scholz, 2010]-either static [e.g., King et al., 1994; Zöller and Hainzl, 2007], dynamic [e.g., Brodsky 2009], related to visco-elastic post-seismic reloading of lower crust and mantle [e.g., Kagan and Jackson, 1991; Chéry et al., 2001a, 2001b; Kenner and Simons, 2005], or resulting from fluctuations in loading rate and creep at the base of the seismogenic crust [e.g., Yeats, 2007; Dolan et al., 2007; Scholz, 2010; Sammis and Smith, 2013], and a combination of some of those factors. Stress transfer from a large earthquake would modify the seismic cycles of the nearby faults having a similar cycle (i.e., similar slip rates and similar recurrence times of large earthquakes), and so doing, would produce an emergent alignment of the fault cycles ("phase locking" of the faults) and hence, the clustering and the synchrony of the large events among the faults [Scholz, 2010; Sammis and Smith, 2013]. In this framework, the synchronizations that we document among the Fucino faults are remarkable from several perspectives. First, they occur at a large scale, as the faults that interact are up to $\sim 30 \mathrm{~km}$ and $\sim 100 \mathrm{~km}$ apart across and along the Fucino network. Second, the synchronized faults are not all parallel (parallelism is one condition taken to favor synchronization [e.g., Scholz, 2010]), as some of them form oblique horsetail terminations of master faults, while the Tre Monti fault is perpendicular to the other faults. Third, the synchronized faults do not slip at the same rates (similar slip rates are another condition taken to favor synchronization [e.g., Scholz, 2010]), with the northern faults being twice faster than the southern faults. It is likely that other faults in the Fucino system are not synchronized with the faults that we analyzed, and even possibly anticorrelated to these faults (as observed in California [Dolan et al., 2007]). More data are needed to examine the spatial extent of the Fucino earthquake synchrony.

\subsubsection{Implications on Fault Slip Rates and on Hazard Assessment}

[101] As long recognized, the observation of clustered earthquakes on faults forces us to reconsider the definition of fault slip rates [e.g., Wallace, 1987; Friedrich et al., 2003; Scholz, 2010]. Obviously, on many faults, strain accumulation and release are strongly time dependent, and hence also must be the fault slip rate [e.g., Friedrich et al., 2003]. Compared to an average long-term estimate, a fault slip rate is expected to be much faster in the periods of clustered seismic activity, and much slower in the longer, more quiescent periods. Therefore, it is reasonable to expect that geodetic, paleoseismological, and geological estimates of fault slip rates might be well different on many faults [e.g., Friedrich et al., 2003].

[102] Our results might contribute to shed a new light on earthquake hazard assessment in central Italy and possibly more broadly. First, as said before, we suggest that large earthquakes are strain predictable, that is, the time and slip of the forthcoming event on a fault might be anticipated from the knowledge of the relative strain level on the fault. Second, the observation of earthquake clustering modifies the anticipation of the forthcoming events: the regions of recent high seismic activity might be those having a larger than usual chance of producing new strong earthquakes (as we may be in a cluster period). Meanwhile, as time increases since the last strong event, the probability increases that we are entering a quieter seismic period [e.g., Wallace, 1987; Kagan and Jackson, 1991]. These inferences are opposite to the classical vision that is generally used in seismic hazard assessment [e.g., McCann et al., 1979; Shimazaki and Nakata, 1980; Nishenko and Buland, 1987]. Third, the finding that most large earthquakes are synchronized in the Fucino network makes seismic hazard even more elevated in this region, as most large earthquakes occur, not as single events, but as groups of connected events striking the entire system in a very short time. Probabilities of future large earthquakes in central Italy should thus be computed, not only from the knowledge of each individual fault, but also by integrating the influence of regional clustering and synchrony [e.g., Wallace, 1987; Cornell et al., 1993; McCalpin and Nishenko, 1996].

\section{Conclusions}

[103] We have recovered the Holocene earthquake history of seven large seismogenic normal faults belonging to the $\sim 50 \mathrm{~km} \times 100 \mathrm{~km}$ Fucino system in central Italy. We collected 800 samples from the well-preserved limestone scarps of the faults and modeled their ${ }^{36} \mathrm{Cl}$ concentrations to derive their seismic exhumation history. This is the largest fault collection ever analyzed so far for paleoseismological purpose, and it is also the largest collection of ${ }^{36} \mathrm{Cl}$ data ever analyzed. We found that $>30$ large earthquakes broke the faults in synchrony over the last $12 \mathrm{ka}$. The seven faults released strain over the same periods of time, 12-9 ka, 5-3 ka, and 1.5-1 ka. On all faults, the strain accumulation and release occurred in 3-6 ka long supercycles, each included a 3-5 ka long phase of strain accumulation at slow rate $(\leq 0.5-2 \mathrm{~mm} / \mathrm{yr})$ and in relative quiescence, followed by a cluster of three to four large earthquakes or earthquake sequences that released most of the strain in less than 1-2 ka. The large earthquakes repeated every $0.5 \pm 0.3 \mathrm{ka}$ during the paroxysmal phases and every $4.3 \pm 0.9 \mathrm{ka}$ between those phases. Earthquakes on the northern faults produced twice larger surface slips $(\sim 2 \mathrm{~m})$ and had larger magnitudes (Mw 6.2-6.7) than those on the southern faults (Mw 5.7-6.6). Faults entered a phase of clustered earthquake activity once they had reached a specific relative strain threshold. On most faults, the relative strain level was found to control the amount of slip and the time of occurrence of the next large earthquake. Our data thus allow to anticipate both the time and the slip of the forthcoming events on the analyzed faults.

[104] Our study adds to a few prior works to suggest that seismic hazard assessment may improve in the near future:

[105] 1. Large earthquakes in the Fucino system do not repeat periodically, yet they are not random either, and they actually repeat in fairly similar sequences (supercycles) that encompass several events. The earthquake occurrence on a fault might thus be regarded as a quasi-periodic process, not at the scale of a single event but at the scale of a cluster of three to five events;

[106] 2. Faults are not individual or independent structures that might be governed by "case-by-case" factors that might be too variable to be approached. On the contrary, faults are organized features that clearly interact and share common 
long-lasting behaviors. Faults are thus governed by some common "laws" which we may hope to understand. In any case, fault interaction must be taken into account in models of seismic hazard;

[107] 3. Large earthquakes are neither slip nor time predictable but they might be strain predictable. Should this finding be generalized, it might offer a key to anticipate more precisely the time and size of the forthcoming events, and hence to markedly improve seismic hazard assessment. Though we believe that the elements above are solid step toward improving our understanding of the earthquake process and our ability to assess seismic hazard, the seismic risk in the Fucino region remains a concern. Whatever the reasons for the synchrony of the Fucino faults, their synchrony makes seismic hazard even more dramatic as large earthquakes obviously occur, not as single events, but as groups of "connected" events striking the (almost) entire Fucino system in a very short time. Furthermore, most or at least certain of the paleo-events that we identified were rather event sequences and not single earthquakes, which suggests that the seismic activity in the Fucino area might be even more elevated than depicted in our study. Finally, our results suggest that some of the analyzed faults are much prone to break in the near future, perhaps over the next century. We suspect this is the case for the Tre Monti fault, that bounds to the north the deep Fucino basin. Though the forthcoming slip anticipated on the fault is moderate $(\sim 0.7 \mathrm{~m})$, the estimated magnitude $(6.0-6.4)$ and the likely shallow depth of this crustal fault might induce strong site effects in the Fucino basin, and hence dramatic damages in this area. We thus suggest that a special attention might be put on the TM fault, as on the other seismogenic faults identified in the zone, to monitor its behavior and possibly get ready when the forthcoming event occurs.

[108] Acknowledgments. Our work has been funded by the INSUCNRS Dyeti program and by the French ANR (project QUAKonSCARPS, ANR-06-CATT-008-01-02-01\&03). We are grateful to the Abruzzo Region archive service in L'Aquila for providing us the aerial pictures, topographical, and geological maps, and to the CNES-Toulouse for providing the SPOT-satellite images through the ISIS program dedicated to the scientific community. National parks and town councils are acknowledged for authorizing us to sample the fault scarps. We warmly thank A. Schlagenhauf, C. Benazet, P. Brenu, E. Canet, J. Carcaillet, R. Grandin, R. Guiguet, S. Hok, H. Lankester, M. and J.M. Maurice, J.M. Nicole, L. Palumbo, F. Renalier, C. Romano, and B. Scalabrino for helping us in the sampling. L. Sevin, J. Marin, and all the staff at SARM-CRPG (France) are acknowledged for the chemical measurements. We are very thankful to T. Guilderson and T. Brown as well as all the staff of the CAMS-LLNL (California), I. Schimmelpfennig, and L. Leanni for their precious assistance and support for the ${ }^{36} \mathrm{Cl}$ measurements. J. Tesson is kindly acknowledged for the topographic profiles. The ASTER French AMS national facility (CEREGE, Aix en Provence) is supported by the INSU/CNRS, the French Ministry of Research and Higher Education, IRD, and CEA. Maps were generated using Generic Mapping Tools (GMT) [Wessel and Smith, 1995]. We are very thankful to the two reviewers, Kate Scharer and Glen Biasi, as well as the associated editor Tom Parsons, for their very constructive and thorough reviews that greatly improved the manuscript.

\section{References}

Akaike, H. (1974), A new look at statistical model identification, IEEE Trans. Automatic Contl., 19(6), 716-723.

Allen, C. R. (1975), Geological criteria for evaluating seismicity, Geol. Soc. Am. Bull., 86, 1041-1057.

Amato, A., et al. (1998), The 1997 Umbria-Marche, Italy, earthquake sequence: a first look at the main shocks and aftershocks, Geophys. Res. Lett., 25, 2861-2864.
Armijo, R., H. Lyon-Caen, and D. Papanastassiou (1992), East-west extension and Holocene normal-fault scarps in the Hellenic arc, Geology, 20(6), 491-494.

Baljinnyam, I., A. Byasgalan, B. A. Borisov, A. Cisternas, M. G. Dem'yanovich, L. Ganbastar, V. M. Kurushin, P. Molnar, H. Philip, and Y. Vashchilov (1993), Ruptures of Major earthquakes and active deformation in Mongolia and its surrounding, Boulder Colorado, Geol. Soc. Of Am. Memoir, 181.

Barka, A. A. (1996), Slip distribution along the North Anatolian fault associated with the large earthquakes of the period 1939-1967, Bull. Seismol. Soc. Am., 86, 1238-1254.

Bell, J. W., S. J. Caskey, A. R. Ramelli, and L. Guerrieri (2004), Pattern and Rates of Faulting in the Central Nevada Seismic Belt, and Paleoseismic Evidence for Prior Beltlike Behavior, Bull. Seismol. Soc. Am., 94, 1229-1254.

Benedetti, L. (1999), Sismotectonique de l'Italie et des regions adjacentes: fragmentation du promontoire adriatique, These de doctorat IPGPUniversité Paris 7.

Benedetti, L., R. Finkel, D. Papanastassiou, G. King, R. Armijo, F. Ryerson, D. Farber, and F. Flerit (2002), Post-glacial slip history of the Sparta fault (Greece) determined by $36 \mathrm{Cl}$ cosmogenic dating: Evidence for non-periodic earthquakes, Geophys. Res. Lett., 29(8), doi:10.1029/2001GL014510.

Benedetti, L., R. Finkel, G. King, R. Armijo, D. Papanastassiou, F. J. Ryerson, F. Flerit, D. Farber, and G. Stavrakakis (2003), Motion of the Kaparelli fault (Greece) prior to the 1981 earthquake sequence determined from 36Cl cosmogenic dating, Terra Nova, 15(2), 118-124.

Ben-Zion, Y., K. Dahmen, V. Lyakhovsky, D. Ertas, and A. Agnon (1999), Self-driven mode switching of earthquake activity on a fault system, Earth Planet. Sci. Lett., 172(1-2), 11-21.

Bernard, P., and A. Zollo (1989), The Irpinia (Italy) 1980 earthquake: Detailed analysis of a complex normal fault, J. Geophys. Res., 94(B2), 1631-1648.

Boschi, E., G. Ferrari, P. Gasperini, E. Guidoboni, G. Smriglio, and G. Valensise (1997), Catalogo dei forti terremoti in Italia dal 461 a.C. al 1980, ING-SGA, Bologna, 973 pp.

Bosi, C. (1975), Osservazioni preliminari su faglie probabilmente attive nell'Appennino centrale, Boll. Soc. Geol. Ital., 94, 827-859.

Brodsky, E. (2009), The 2004-2008 worldwide superswarm, EOS Trans $A G U$ 90, Fall Meeting (Suppl), abstract S53B-06.

Bucknam, S. T., R. C. Algermissen, and R. E. Anderson (1980), Patterns of late Quaternary faulting in western Utah and an application in earthquake hazard evaluation, Andriese, PD, compiler, Earthquake hazards along the Wasatch and Sierra-Nevada frontal fault zones: US Geological Survey Open-File Report, 80-801.

Bufe, G., and D. M. Perkins (2005), Evidence for a Global Seismic-Moment Release Sequence, Bull. Seismol. Soc. Am., 95(3), 833-843, doi:10.1785/ 0120040110 .

Cavinato, G. P., C. Carusi, M. Dall'Asta, E. Miccadei, and T. Piacentini (2002), Sedimentary and tectonic evolution of Plio-Peistocene alluvial and lacustrine deposits of Fucino Basin (central Italy), Sediment. Geol., $148,29-59$.

Chéry, J., S. Merkel, and S. Bouissou (2001a), A Physical Basis for Time Clustering of Large Earthquakes, Bull. Seismol. Soc. Am., 91(6), 1685-1693.

Chéry, J., S. Carretier, and J. F. Ritz (2001b), Postseismic stress transfer explains time clustering of large earthquakes in Mongolia, Earth Planet. Sci. Lett., 194, 277-286.

Chiarabba, C., et al. (2009), The 2009 L'Aquila (central Italy) MW6.3 earthquake: main shock and aftershocks, Geophys. Res. Lett., 36, L18308, doi:10.1029/2009GL039627.

Chiaraluce L., C. Chiarabba, P. De Gori, R. Di Stefano, L. Improta, D. Piccini, A. Schlagenhauf, P. Traversa, L. Valoroso, and C. Voisin (2011), The 2009 L'Aquila (central Italy) seismic sequence, Bollettino di Geofisica Teorica e Applicata, Volume spécial « The Abruzzo Earthquake», eds. A. Amato, P. Galli, M. Mucciarelli.

Cornell, C. A., W. Shen-Chyun, S. R. Winterstein, J. H. Dieterich, and R. W. Simpson (1993), Seismic hazard induced by mechanically interactive fault segments, Bull. Seismol. Soc. Am., 83(2), 436-449.

D’Addezio, G., E. Masana, and D. Pantosti (2001), The Holocene paleoseismicity of the Aremogna-Cinque Miglia fault (central Italy), J. seismo., 5, 181-205.

D’Agostino, N., J. A. Jackson, F. Dramis, and R. Funiciello (2001), Interactions between mantle upwelling, drainage evolution and active normal faulting: an example from the central Apennines (Italy), Geophys. J. Int., 147, 457-497.

D’Agostino, N., A. Avallone, D. Cheloni, E. D’Anastasio, S. Mantenuto, and G. Selvaggi (2008), Active tectonics of the Adriatic region from GPS and earthquake slip vectors, J. Geophys. Res., 113, B12413, doi:10.1029/2008JB005860.

Dolan, J., D. Bowman, and C. Sammis (2007), Long-range and longterm fault interactions in Southern California, Geology, 35(9), $855-858$. 
Faenza, L., W. Marzocchi, A. M. Lombardi, and R. Console (2004), Some insights into the time clustering of large earthquakes in Italy, Ann. Geophys., 47(5), 1635-1640.

Ferry, M., M. Meghraoui, N. Abou Karaki, M. Al-Taj, H. Amoush, S. Al-Dhaisat, and M. Barjous (2007), A 48-kyr-long slip rate history for the Jordan Valley segment of the Dead Sea fault, Earth Planet. Sci. Lett., 260, 394-406.

Ferry, M., M. Meghraoui, N. Abou Karaki, M. Al-Taj, and L. Khalil (2011), Episodic behavior of the Jordan Valley section of the Dead Sea fault from a 14-kyr-long integrated catalogue of large earthquakes, Bull. Seismol. Soc. Am., 101(1), 39-67.

Friedrich, A., B. P. Wernicke, N. A. Niemi, R. A. Bennett, and J. L. Davis (2003), Comparison of geodetic and geologic data from the Wasatch region, Utah, and implications for the spectral character of Earth deformation at periods of 10 to 10 million years, J. Geophys. Res., 108(B4), 2199, doi:10.1029/2001JB000682.

Galadini, F., and P. Galli (1999), The Holocene paleoearthquakes on the 1915 Avezzano earthquake faults (central Italy): Implications for active tectonics in central Italy, Tectonophysics, 308, 143-170.

Galadini, F., and P. Galli (2000), Active tectonics in the Central Apennines (Italy) - Input data for seismic hazard assessment, Nat. Hazards, 22, $225-270$.

Galadini, F., and P. Messina (1994), Plio-Quaternary tectonics of the Fucino basin and surroundings area (central Italy), G. Geol., 56(2), 73-99.

Galadini, F., P. Galli, and M. Moro (2003), Paleoseismology of silent faults in the Central Apennines (Italy): The Campo Imperatore fault (Gran Sasso range fault system), Ann. Geophys., 46(5), 793-813.

Galadini, F., E. Ceccaroni, and E. Falcucci (2010), Archaeoseismological evidence of a disruptive Late Antique earthquake at Alba Fucens (central Italy), B. Geofis. Teor. Appl., 51(2-3), 143-161.

Ghisetti, F., and L. Vezzani (2002), Normal faulting, extension and uplift in the outer thrust belt of the central Apennines (Italy): Role of the Caramanico fault, Basin Res., 14, 225-236.

Giraudi, C. (1998), The late Quaternary geologic evolution of Campo Felice (Abruzzo, central Italy), G. Geol., 60, 67-82.

Giraudi, C., and M. Frezzotti (1995), Paleoseismicity in the Gran Sasso Massif (Abruzzo, central Italy), Quaternary Int., 25, 81-93.

Goes, S. (1996), Irregular recurrence of large earthquakes: An analysis of historic and paleoseismic catalogs, J. Geophys. Res., 101(B3), 5739-5749.

Grant, L. B., and K. Sieh (1994), Paleoseismic evidence of clustered earthquakes on the San Andreas Fault in the Carrizo Plain, California, J. Geophys. Res., 99(B4), 6819-6841, doi:10.1029/94JB00125.

Gruppo di Lavoro CPTI (2004), Catalogo Parametrico dei Terremoti Italiani, Versione 2004 (CPTI04), INGV. Bologna.

Guidoboni, E., G. Ferrari, D. Mariotii, A. Comastri, G. Tarabusi, and G. Valensise (2007), CFT14Med, Catalogue of Strong Earthquakes in Italy (461 B.C. - 1997) and Mediterranean area (760 B.C. - 1500), $I N G V$-SGA, Bologna, Available at http://storing. ingv.it/cfti4med/.

Haibing, L., J. Van der Woerd, P. Tapponnier, Y. Klinger, Q. Xuexiang, Y. Jingsuia, and Z. Yintang (2005), Slip rate on the Kunlun fault at Hongshui Gou, and recurrence time of great events comparable to the 14/11/2001, Mw 7.9 Kokoxili earthquake, Earth Planet. Sci. Lett., 237, (1-2), 30 August 2005, 285-299.

Holbrook, J., W. J. Autin, T. M. Rittenour, S. Marshak, and R. J. Goble (2006), Stratigraphic evidence for millennial-scale temporal clustering of earthquakes on a continental-interior fault: Holocene Mississippi River floodplain deposits, New Madrid seismic zone, USA, Tectonophysics, 420, 431-454.

Hunstad, I., G. Selvaggi, N. D’Agostino, P. England, P. Clarke, and M. M. Pierozzi (2003), Geodetic strain in peninsular Italy between 1875 and 2001, Geophys. Res. Lett., 30, 1181, doi:10.1029/2002GL016447, 4.

Jacques, E., T. Kidane, P. Tapponnier, I. Manighetti, Y. Gaudemer, and B. Meyer (2011), Normal faulting during the August 1989 earthquakes in Central Afar: Sequential triggering and propagation of rupture along the Dôbi Graben, Bull. Seismol. Soc. Am., 101, 994-1023, doi:10.1785/0120080317.

Kagan, Y. Y., and D. Jackson (1991), Long-term earthquake clustering, Geophys. J. Int, 104, 117-133.

Kagan, Y. Y., et al. (2012), Characteristic Earthquake Model, Seismol. Res. Lett., 83(6), 1884-2011, doi:10.1785/0220120107.

Kenner, S., and M. Simons (2005), Temporal clustering of major earthquakes along individual faults due to post-seismic reloading, Geophys. $J$. Int., 160(1), 179-194.

King, G. C. P., R. S. Stein, and J. Lin (1994), Static stress changes and the triggering of earthquakes, Bull. Seismol. Soc. Am., 84(3), 935-953.

Klinger, Y., M. Etchebes, P. Tapponnier, and C. Narteau (2011), Characteristic slip for five great earthquakes along the Fuyun fault in China, Nat. Geosci., 4(6), 389-392.

Lowell, T. V. (1995), The application of radiocarbon age estimates to the dating of glacial sequences: an example from the Miami sublobe, Ohio, USA, Quat. Sci. Rev., 14, 85-99.
Ludwig, K. R. (2003), Isoplot 3.00 - a user's manual, Berkeley Geochronology Center Special Publication.

Lynch, J. C., R. Bürgmann, and M. A. Richards (2003), When faults communicate: Viscoelastic coupling and earthquake clustering in a simple two-fault system, Geophys. Res. Lett., 30(6), 1270, doi:10.1029/2002GL016765.

Manighetti, I., P. Tapponnier, V. Courtillot, and Y. Gallet (2001a), Strain transfer between disconnected, propagating rifts in Afar, J. Geophys. Res., 106(B7), 13,613-13,665.

Manighetti, I., G. C. P. King, Y. Gaudemer, C. Scholz, and C. Doubre (2001b), Slip accumulation and lateral propagation of active normal faults in Afar, J. Geophys. Res., 106, 13,667-13,696.

Manighetti, I., M. Campillo, C. Sammis, P. M. Mai, and G. C. P. King (2005), Evidence for self-similar, triangular slip distributions on earthquakes: Implications for earthquake and fault mechanics, J. Geophys. Res., 110, B05302, doi:10.1029/2004JB003174.

Manighetti, I., M. Campillo, S. Bouley, and F. Cotton (2007), Earthquake scaling, fault segmentation, and structural maturity, Earth Planet. Sci. Lett., 253, 429-438.

Manighetti, I., D. Zigone, M. Campillo, and F. Cotton (2009), Self-similarity of the largest-scale segmentation of the faults: Implications for earthquake behavior, Earth Planet. Sci. Lett., 288(3-4), 370-381.

Marco, S., M. Stein, and A. Agnon (1996), Long-term earthquake clustering: a 50,000-year paleoseismic record in the Dead Sea Graben, J. Geophys. Res., 101(B3), 6179-6191.

McCalpin, J. P., and S. P. Nishenko (1996), Holocene paleoseismicity, temporal clustering, and probabilities of future large $(\mathrm{M}>7)$ earthquakes on the Wasatch fault zone, Utah, J. Geophys. Res., 101(B3), 6233-6253, doi:10.1029/95JB02851.

McCann, W. R., S. P. Nishenko, L. R. Sykes, and J. Krause (1979), Seismic gaps and plate tectonics: seismic potential for maior boundaries, Pure Appl. Geophys., 117, 1082-1147.

Meltzner, A. J., K. Sieh, H. W. Chiang, C. C. Shen, B. W. Suwargadi, D. H. Natawidjaja, B. E. Philibosian, R.W. Briggs, and J. Galetzkal (2010), Coral evidence for earthquake recurrence and an A.D. 1390-1455 cluster at the south end of the 2004 Aceh-Andaman rupture, J. Geophys. Res., 115, B10402, doi:10.1029/2010JB007499.

Michetti, A. M., F. Brunamonte, L. Serva, and E. Vittori (1996), Trench investigations of the 1915 Fucino earthquake fault (Abruzzo, central Italy): Geological evidence of large historical events, J. Geophys. Res., 101, 5921-5936.

Mitchell, S. G., A. Matmon, P. R. Bierman, Y. Enzel, M. Caffee, and D. Rizzo (2001), Displacement history of a limtesone normal fault scarp, northern Israel, from cosmogenic 36Cl, J. Geophys. Res., 106(B3), 4247-4264.

Nishenko, S. P., and R. Buland (1987), A generic recurrence interval distribution for earthquake forecasting, Bull. Seismol. Soc. Am., 77(4) 1382-1399.

Nocquet, J. M., and E. Calais (2004), Geodetic Measurements of Crustal Deformation in the Western Mediterranean and Europe, Pure and Appl. Geophys, 161, 661-681.

Nur, A., and E. H. Cline (2000), Poseidon's horses: Plate tectonics and earthquake storms in the Late Bronze Age Aegean and Eastern Mediterranean, J. Archaeol. Sci., 27, 43-63.

Oddone, E. (1915), Gli elementi fisici del grande terremoto MarsicanoFucense del 13 Gennaio 1915, Boll. Soc. Sism. Ital., 19, 71-216.

Palumbo, L., L. Benedetti, D. Bourlès, A. Cinque, and R. Finkel (2004), Slip history of the Magnola fault (Apennines, central Italy) from $36 \mathrm{Cl}$ surface exposure dating: evidence for strong earthquake over the Holocene, Earth Planet. Sci. Lett., 225, 163-176.

Pantosti, D., G. D'Addenzio, and F. R. Cinti (1996), Paleoseismicity of the Ovindoli-Pezza fault, central Apennines, Italy: a history including a large, previously unrecorded earthquake in the Middle Ages (860-1300 AD), $J$. Geophys. Res., 101, 5937-5959.

Parsons, T. (2008), Earthquake recurrence on the south Hayward fault is most consistent with a time dependent, renewal process, Geophys. Res Lett., 35, L21301, doi:10.1029/2008GL035887.

Phillips, F. M., W. D. Stone, and J. T. Fabryka-Martin (2001), An improved approach to calculating low-energy cosmic-ray neutron fluxes near the land/atmosphere interface, Chem. Geol., 175, 689-701.

Piccardi, L., Y. Gaudemer, P. Tapponnier, and M. Boccaletti (1999), Active oblique extension in the central Apennines (Italy): Evidence from the Fucino region, Geophys. J. Int., 139, 499-530.

Pirazzoli, P. A., J. Laborel, and S. C. Stiros (1996), Earthquake clustering in the Eastern Mediterranean during historical times, J. Geophys. Res., 101(B3), 6083-6097.

Pizzi, A., and F. Galadini (2009), Pre-existing cross-structures and active fault segmentation in the northern-central Apennines (Italy), Tectonophysics, 476(1-2), 304-319, doi:10.1016/j.tecto.2009.03.018.

Pizzi, A., and G. Pugliese (2004), InSAR-DEM analyses integrated with geologic field methods for the study of long- term seismogenic fault 


\section{BENEDETTI ET AL.: LARGE EARTHQUAKES IN CENTRAL ITALY}

behavior: Applications in the axial zone of the central Apennines (Italy), J. Seismol., 8, 313-329.

Reid, H. F. (1910), The mechanics of the earthquake, the California earthquake of April 18, 1906, Report State Investig. Comm., vol. 2, Carnegie Inst., Washington.

Rockwell, T. K., S. Lindvall, M. Herzberg, D. Murbach, T. Dawson, and G. Berger (2000), Paleoseismology of the Johnson Valley, Kickapoo, and Homestead Valley faults: Clustering of earthquakes in the eastern California shear zone, Bull. Seismol. Soc. Am., 90(5), 1200-1236.

Salvi, S., and A. Nardi (1995), The Ovindoli fault: A segment of a longer, active fault zone in central Abruzzi, Italy. In Perspectives in Paleoseismology 6, Eds Serva and Slemmons, DB, Bull. Assoc. Eng. Geol., 6, 101-113.

Salvi, S., F. R. Cinti, L. Colini, G. D'Addezio, F. Doumaz, and E. Pettinelli (2003), Investigation of the active Celano-L'Aquila fault system, Abruzzi (central Apennines, Italy) with combined ground-penetrating radar and paleoseismic trenching, Geophys. J. Int., 155, 805-818.

Sammis, C. G., and S. W. Smith (2013), Triggered tremor, phase-locking, and the global clustering of great earthquakes, Tectonophysics, 589, $167-171$.

Scharer, K. M., G. P. Biasi, R. J. Weldon, and T. E. Fumal (2010), Quasiperiodic recurrence of large earthquakes on the southern San Andreas fault, Geology, 38(6), 555-558.

Scharer, K. M., G. P. Biasi, and R. J. Weldon (2011), A reevaluation of the Pallett Creek earthquake chronology based on new AMS radiocarbon dates, San Andreas fault, California, J. Geophys. Res., 116(B12), 1978-2012, doi:10.1029/2010JB008099.

Schimmelpfennig, I., L. Benedetti, R. Finkel, R. Pik, P. H. Blard, D. Bourlès, P. Burnard, and A. Williams (2009), Sources of in- situ 36Cl in basaltic rocks. Implications for calibration of production rates, Quatern. Geochronol., 4, 441-461.

Schimmelpfennig, I., L. Benedetti, V. Garreta, R. Pik, P.-H. Blard, P. Burnard, D. Bourlès, R. Finkel, K. Ammon, and T. Dunai (2011), Calibration of cosmogenic $36 \mathrm{Cl}$ production rates from $\mathrm{Ca}$ ans $\mathrm{K}$ spallation in lava flows from Mt. Etna $\left(38^{\circ} \mathrm{N}\right.$, Italy) and Payun Matru $\left(36^{\circ} \mathrm{S}\right.$, Argentina), Geochim. Cosmochim. Acta, doi:10.1016/j.gca.2011.02.013.

Schlagenhauf, A., I. Manighetti, J. Malavieille and S. Dominguez (2008), Incremental growth of normal faults: Insights from a laser-equipped analog experiment, Earth Planet. Sci. Lett., 273, 299-311.

Schlagenhauf, A., Y. Gaudemer, L. Benedetti, I. Manighetti, L. Palumbo, I. Schimmelpfennig, R. Finkel, and K. Pou (2010), Using in situ Chlorine-36 cosmonuclide to recover past earthquake histories on limestone normal fault scarps: A reappraisal of methodology and interpretations, Geophys. J. Int., doi:10.1111/j.1365-246X.2010.04622.x.

Schlagenhauf, A., I. Manighetti, L. Benedetti, Y. Gaudemer, R. Finkel, J. Malavieille, and K. Pou (2011), Earthquake supercycles in central Italy,inferred from $36 \mathrm{Cl}$ exposure dating, Earth Planet. Sci. Lett., 307, 487-500.

Scholz, C. (2010), Large Earthquake Triggering, Clustering, and the Synchronization of Faults, Bull. Seismol. Soc. Am., 100(3), 901-909, doi:10.1785/0120090309.

Schwartz, D., and K. Coppersmith (1994), New Empirical Relationships among Magnitude, Rupture Length, Rupture Width, Rupture Area, and Surface Displacement, Bull. Seismol. Soc. Am., 84(4), 974-1002.

Serpelloni, E., G. Vannucci, S. Pondrelli, A. Argnani, G. Casula, M. Anzidei, P. Baldi, and P. Gasperini (2007), Kinematics of the Western Africa-Eurasia plate boundary from focal mechanisms and GPS data, Geophys. J. Int., 169, $1180-1200$.

Sharma, P., P. W. Kubik, U. Fehn, H. E. Gove, K. Nishiizumi, and D. Elmore (1990), Development of 36Cl standards for AMS, Nucl. Instrum. Meth. Phys. Res., Sect. B, 52, 410-415.
Shimazaki, K., and T. Nakata (1980), Time-predictable recurrence model for large earthquakes, Geophys. Res. Lett., 7(4), 279-282.

Sieh, K. E. (1984), Lateral offsets and revised dates of large prehistoric earthquakes at Pallett Creek, southern California, J. Geophys. Res., 89(B9), $7641-7670$.

Sieh, K. (1996), The repetition of large-earthquake ruptures, Proc. Natl. Acad. Sci. U. S. A., 93(9), 3764-3771.

Sieh, K., D. H. Natawidjaja, A. J. Meltzner, C.-C. Shen, H. Cheng, K.-S. Li, B. W. Suwargadi, J. Galetzka, B. Philibosian, and L. Edwards (2008), Earthquake Supercycles inferred from sea-level changes recorded in the corals of west Sumatra, Science, 322, 1674-1678.

Sornette, D., and L. Knopoff (1997), The paradox of the expected time until the next earthquake, Bull. Seismol. Soc. Am., 87(4), 789-798.

Stein, R. S., A. A. Barka, and J. H. Dieterich (1997), Progressive failure on the North Anatolian fault since 1939 by earthquake stress triggering, Geophys. Jour. Int.l, 128(3), 594-604.

Stiros, S. C. (2001), The AD 365 Crete earthquake and possible seismic clustering during the fourth to sixth centuries $\mathrm{AD}$ in the Eastern Mediterranean: A review of historical and archaeological data, J. Struct. Geol., 23(2), 545-562.

Stone, J. O. (2000), Air pressure and cosmogenic isotope production, J. Geophys. Res., 105(B10), 23,753-23,759.

Stone, J. O., G. L. Allan, L. K. Fifield, and R. G. Cresswell (1996), Cosmogenic chlorine-36 from calcium spallation, Geochim. Cosmochim. Acta, 60(4), 679-692.

Stucchi, M., et al. (2007), DBMI04, il database delle osservazioni macrosismiche dei terremoti italiani utilizzate per la compilazione del catalogo parametrico CPTI04, Quaderni di Geofisica, 49, 38, http:// emidius.mi.ingv.it/DBMI04/.

Tapponnier, P., and P. Molnar (1977), Active faulting and tectonics in China, J. Geophys. Res., 82(20), 2905-2930.

Tapponnier, P., F. J. Ryerson, J. Van der Woerd, A. S. Mériaux, and C. Lasserre (2001), Long-term slip rates and characteristic slip: Keys to active fault behaviour and earthquake hazard, C.R. Acad. Sci., Ser. IIa-Earth Planet. Sci., 333(9), 483-494.

Vanneste, K., A. Radulov, P. De Martini, G. Nikolov, T. Petermans, K. Verbeeck, T. Camelbeeck, D. Pantosti, D. Dimitrov, and S. Shanov (2006), Paleoseismologic investigation of the fault rupture of the 14 April 1928 Chirpan earthquake (M 6.8), southern Bulgaria, J. Geophys. Res., 111, B01303, doi:10.1029/2005JB003814.

Vezzani, L., and F. Ghisetti (1998), Carta Geologica dell'Abruzzo, Regione Abruzzo, Scala 1:100000.

Wallace, R. E. (1977), Profiles and ages of young fault scarps, north-central Nevada, Bull. Seismol. Soc. Am., 88, 1267-1281.

Wallace, R. (1987), Grouping and migration of surface faulting and variations in slip rates on faults in the Great Basin province, Bull. Seismol. Soc. Am., 77(3), 868-876.

Weldon, R. J., K. M. Scharer, T. E. Fumal, and G. P. Biasi (2004), Wrigthwood and the earthquake cycle: What a long record tells us about how fault works, GSA Today, 14, 4.

Wesnousky, S. G. (1994), The Gutenberg-Richter or characteristic earthquake distribution, which is it?, Bull. Seismol. Soc. Am., 84(6), 1940-1959.

Westaway, R. (1993), Quaternary Uplift of Southern Italy, J. Geophys. Res., 98(B12), 21,741-21, 772 .

Yeats, R. (2007), Paleoseismology: Why can't earthquakes keep on schedule?, Geology, 35(9), 863-864, doi:10.1130/focus092007.1.

Zöller, G., and S. Hainzl (2007), Recurrence time distributions of large earthquakes in a stochastic model for coupled fault systems: the role of fault interaction, Bull. Seismol. Soc. Am., 97, 1679-1687, doi:10.1785/ 0120060262 . 